\title{
Application of a global nonhydrostatic model with a stretched-grid system to regional aerosol simulations around Japan
}

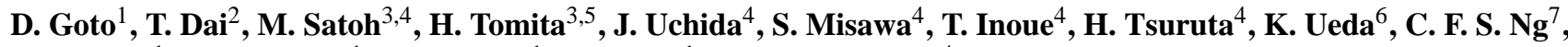

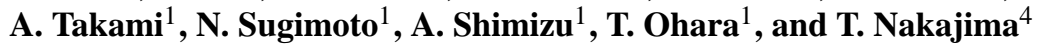 \\ ${ }^{1}$ National Institute for Environmental Studies, Tsukuba, Japan \\ ${ }^{2}$ State Key Laboratory of Numerical Modeling for Atmospheric Sciences and Geophysical Fluid Dynamics, \\ Institute of Atmospheric Physics, Chinese Academy of Sciences, Beijing, China \\ ${ }^{3}$ Japan Agency for Marine-Earth Science and Technology, Yokohama, Japan \\ ${ }^{4}$ Atmosphere and Ocean Research Institute, University of Tokyo, Kashiwa, Japan \\ ${ }^{5}$ Advanced Institute for Computational Science, RIKEN, Kobe, Japan \\ ${ }^{6}$ Faculty of Engineering, Kyoto University, Kyoto, Japan \\ ${ }^{7}$ Department of Human Ecology School of International Health Graduate School of medicine, \\ University of Tokyo, Tokyo, Japan
}

Correspondence to: D. Goto (goto.daisuke@nies.go.jp)

Received: 15 November 2013 - Published in Geosci. Model Dev. Discuss.: 8 January 2014

Revised: 9 January 2015 - Accepted: 19 January 2015 - Published: 11 February 2015

\begin{abstract}
An aerosol-coupled global nonhydrostatic model with a stretched-grid system has been developed. Circulations over the global and target domains are simulated with a single model, which includes fine meshes covering the target region to calculate meso-scale circulations. The stretched global model involves lower computational costs to simulate atmospheric aerosols with fine horizontal resolutions compared with a global uniform nonhydrostatic model, whereas it may require higher computational costs compared with the general regional models, because the stretched-grid system calculates inside and outside the target domain. As opposed to general regional models, the stretched-grid system requires neither a nesting technique nor lateral boundary conditions. In this study, we developed a new-type regional model for the simulation of aerosols over Japan, especially in the Kanto areas surrounding Tokyo, with a maximum horizontal resolution of approximately $10 \mathrm{~km}$. This model usually reproduces temporal variations and their averages of the observed weather around Japan. This model generally reproduces monthly mean distributions of the observed sulfate and $\mathrm{SO}_{2}$ over East Asia, with high correlations $(R>0.6)$, but the underestimation of the simulated concentrations by $40 \%$ (sulfate) and $50 \%\left(\mathrm{SO}_{2}\right)$. Their underestimation of the simulated sulfate and $\mathrm{SO}_{2}$ concentrations over East Asia are
\end{abstract}

strongly affected by their underestimation in China and possibly by the uncertainty of the simulated precipitation around Japan. In the Kanto area, this model succeeds in simulating the wind patterns and the diurnal transitions around the center of the Kanto area, although it is inadequate to simulate the wind patterns and the diurnal transitions at some sites located at the edge of the Kanto area and surrounded on three sides by mountains, e.g., Maebashi, mainly due to the insufficient horizontal resolution. This model also generally reproduces both diurnal and synoptic variations of the observed and/or a regional aerosol-transport model, WRF-CMAQ, simulated $\mathrm{EC}$, sulfate, and $\mathrm{SO}_{2}$ concentrations in the Kanto area, especially with their high correlation $(R>0.5)$ at Komae/Tokyo. Although the aerosol module used in this study is relatively simplified compared to the general regional aerosol models, this study reveals that our proposed model with the stretchedgrid system can be applicable for the regional aerosol simulation. 


\section{Introduction}

Aerosols can greatly affect regional air quality and contribute to global climate change (Forster et al., 2007). Recently, transboundary aerosol pollution, whereby regions beyond a given country's borders are affected by the aerosols generated in that country, has been of increasing concern (Ramanathan et al., 2008; Yu et al., 2012). The ongoing rapid economic growth in developing countries has the potential to exacerbate this issue (UNEP and WMO, 2011). Air pollution generated by aerosols is a critical public health issue due to the deleterious effects of these particles on human health (Dockery et al., 1993; Pope III et al., 2009). Aerosols, which scatter and absorb solar radiation and act as cloud condensation nuclei, can directly and indirectly change the Earth's radiation budget. The majority of aerosols are emitted from localized areas, which are referred to as hotspots, such as megacities and biomass-burning regions, and are spread throughout the world via atmospheric transport (e.g., Ramanathan et al., 2008). Therefore, global aerosol-transport models should consider the important regional-scale characteristics of aerosol hotspots to estimate their impacts on air quality and climate change reliably.

Most existing global aerosol-transport models do not address the spatial variability of aerosols in the vicinity of hotspots due to their coarse horizontal resolution of 100 $300 \mathrm{~km}$ (Kinne et al., 2006; Textor et al., 2006). In addition, global aerosol-transport models with coarse resolutions frequently adopt a spectral transform method with a hydrostatic approximation to effectively calculate atmospheric dynamics. This spectral transform method is less effective than the grid-point method (Stuhne and Peltier, 1996; Taylor et al., 1997; Randall et al., 2000) for high horizontal resolutions (Tomita et al., 2008). Models that employ the grid-point method flexibly define grid points to enable an adaptive focus on study regions. Thus, global models based on the gridpoint method seem most appropriate for use in simulating aerosol transport from hotspots to outflow regions.

For this purpose, we utilized the global Nonhydrostatic Icosahedral Atmospheric Model (NICAM) developed by Tomita and Satoh (2004) and Satoh et al. (2008). NICAM has been employed for the global simulation of atmospheric processes with high-resolution grid spacing, whose size is comparable to the typical deep convective cloud scale. Miura et al. (2007) performed a 1 week computation with a horizontal resolution of $3.5 \mathrm{~km}$ using the Earth Simulator at the Japan Agency for Marine-Earth Science and Technology (JAMSTEC) to successfully simulate a Madden-Julian Oscillation (MJO) event. Suzuki et al. (2008) implemented an aerosol transport model named the Spectral RadiationTransport Model for Aerosol Species (SPRINTARS; Takemura et al., 2005) in NICAM (we refer to this aerosolcoupled model as NICAM-SPRINTARS) and performed a 1 week simulation with a horizontal resolution of $7 \mathrm{~km}$ using the Earth Simulator. Although these global, highly resolved calculations are promising with regard to long-term climate simulations for decades, their requirement of vast computer resources substantially limits their use in short-duration and/or case-specific simulations due to the current limitations of computational resources. To overcome this limitation, we adopt a compromise approach based on a new grid transformation named the stretched grid system, which was developed and implemented in NICAM by Tomita (2008a) for computationally effective simulations in the target region (see, also, Satoh et al., 2010). We applied this approach to NICAM-SPRINTARS, which we named Stretch-NICAMSPRINTARS, to calculate aerosol transport processes with high horizontal resolutions over aerosol source regions.

In this study, we focused on Japan, especially the Kanto region surrounding Tokyo (Fig. 1), because the Kanto region in which more than 30 million people live is one of the largest megacities in the world. In Japan, a monitoring system for the air pollution, e.g., $\mathrm{PM}_{2.5}$ (aerosol particles with diameters less than $2.5 \mu \mathrm{m}$ ) and $\mathrm{SO}_{2}$, has been operated by the Japanese government. Inorganic ions, mainly sulfate, have been measured over Japan and other Asian countries under EANET (Acid Deposition Monitoring Network in East Asia; http://www.eanet.asia/index.html). Measurements of carbonaceous aerosols were limited, with the exception of intensive measurements (Fine Aerosol Measurement and Modeling in Kanto Area, FAMIKA) in the Kanto region during summer 2007 (Hasegawa et al., 2008; Fushimi et al., 2011). For the model evaluation using these measurements, we simulated aerosol spatial distributions during August 2007 using Stretch-NICAM-SPRINTARS with a horizontal resolution of approximately $10 \mathrm{~km}$ over the Kanto region. Because the model framework of Stretch-NICAM-SPRINTARS is identical to that of globally uniformed grid simulation (we named it Global-NICAM-SPRINTARS), with the exception of the grid configuration, and involves lower computational costs than global simulations, the investigation of the model performance of Stretch-NICAM-SPRINTARS can be simply and effectively extended to improve the original NICAMSPRINTARS with globally uniform high resolution for nearfuture simulations. To evaluate aerosol simulations with the stretched-grid system, in this study we also conducted Global-NICAM-SPRINTARS, but with relatively low resolution (approximately $100 \mathrm{~km}$ ) due to the limited computational resources. The model intra-comparison approach, with the exception of the grid system and the spatial resolution, is very meaningful to investigate impacts of the stretchedgrid system on the aerosol simulations. In addition, StretchNICAM-SPRINTARS can be a new-type model that is also applicable for a regional simulation of aerosols, because it focuses on a specific regional domain without requiring a nesting technique or boundary conditions, unlike general regional models.

For the model evaluation in the target, Japan, we mainly focused on a representative primary aerosol, i.e., elemental carbon (EC), and a representative secondary aerosol, i.e., sul- 
(a) East Asia

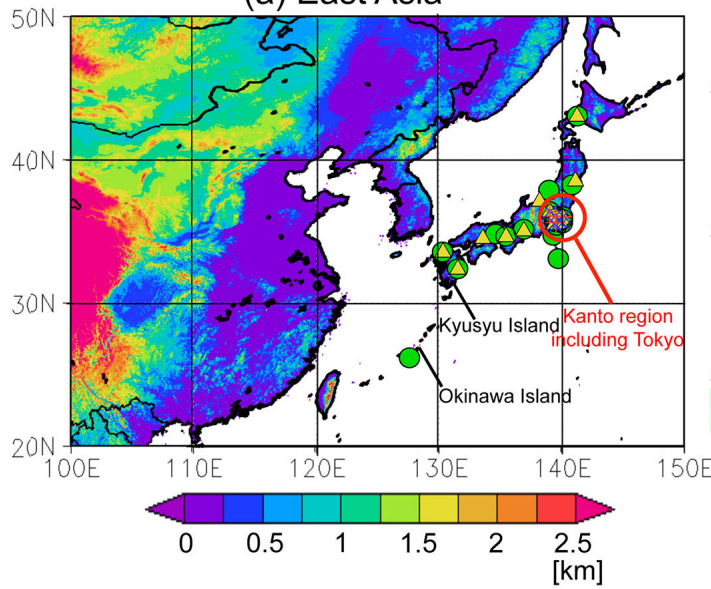

(b) Eastern Japan

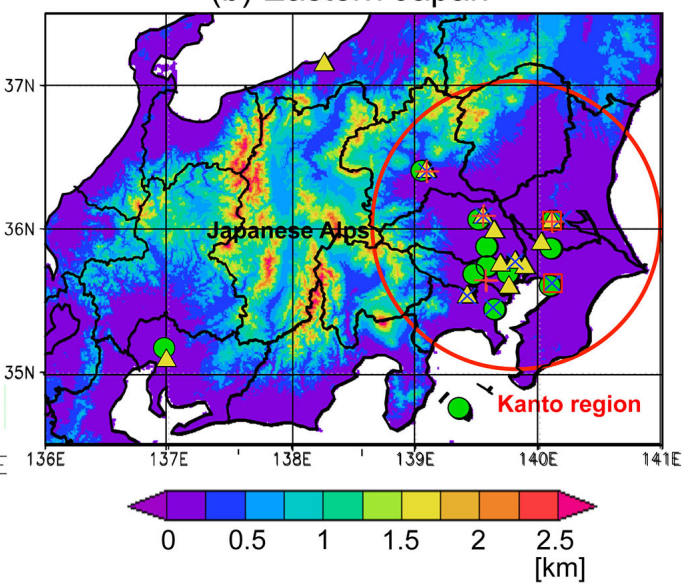

كـ : FAMIKA sites (Aerosol chemical species) including 4 sites; Maebashi $\left(139.10^{\circ} \mathrm{E}, 36.40^{\circ} \mathrm{N}\right.$ ), Kisai $\left(139.56^{\circ} \mathrm{E}, 36.09^{\circ} \mathrm{N}\right)$, Komae $\left(139.58^{\circ} \mathrm{E}, 35.64^{\circ} \mathrm{N}\right)$, Tsukuba $\left(140.12^{\circ} \mathrm{E}, 36.05^{\circ} \mathrm{N}\right)$

X : 7 Sites (Meteorology measurements)

: 21 Sites (Precipitation measurements by AMeDAS)

$\triangle: 18$ Sites $\left(\mathrm{PM}_{2.5}\right.$ measurements)

$: 2$ Sites (LIDAR measurements)

Figure 1. Topographical maps of (a) East Asia and (b) eastern Japan, including the observation sites for the model validation. The topography is based on GTOPO30 (the horizontal resolution is $30 \mathrm{arc} \mathrm{s}$, that is, approximately $1 \mathrm{~km}$ ) courtesy of the US Geological Survey.

fate. EC is directly emitted from anthropogenic combustion processes, and is a good indicator to monitor the transport pattern. The global and regional modelings for sulfate, which is formed from $\mathrm{SO}_{2}$ in the atmosphere, are more deeply understood compared to modelings for the other secondary aerosols such as nitrate and organic aerosols (e.g., Barrie et al., 2001; Holloway et al., 2008; Hallquist et al., 2009; Morino et al., 2010a, b). In addition, sulfate is the largest contributor to the total secondary inorganic aerosols (e.g., Zhang et al., 2007), and the sulfate mass concentrations are larger than that the nitrate ones in August 2007 over the Kanto area (Morino et al., 2010c). Originally, these basic components (EC and sulfate) were suitable for the evaluation in this study, primarily because the stretched-grid system was applied to the simulations of atmospheric pollutants over the land in the mid-latitude bond for the first time and secondly because the original SPRINTARS is more simplified compared to conventional regional aerosol models.

This paper is organized as follows: the model framework of NICAM and SPRINTARS and the experimental design are described in Sect. 2. We show two model results: (1) StretchNICAM-SPRINTARS with glevel-6, in which "glevel" is the number of divisions of an icosahedron used to construct the horizontal grid (hereafter referred to as the "NICAMg6str" model), and (2) Global-NICAM-SPRINTARS with glevel-6 (hereafter referred to as the "NICAM-g6" model). In Sect. 3, the model results are validated using in situ measurements in terms of meteorological fields including precipitation and aerosol species, especially EC, sulfate and $\mathrm{SO}_{2}$. For the model evaluation of chemical species, we also made use of results in a regional aerosol model, the Community
Multiscale Air Quality (CMAQ) driven by the Weather Research and Forecasting (WRF) model named WRF-CMAQ, shown by Shimadera et al. (2013). We also present the validation of total aerosol amounts, i.e., $\mathrm{PM}_{2.5}$, and aerosol optical product, i.e., extinction for spherical aerosols. Finally, the conclusions are summarized in Sect. 4.

\section{Model description}

\subsection{Nonhydrostatic Icosahedral Atmospheric Model (NICAM)}

NICAM, which employs an icosahedral grid-point method with a nonhydrostatic equation system (Tomita and Satoh, 2004; Satoh et al., 2008, 2014), is run with a maximum horizontal resolution of $3.5 \mathrm{~km}$ (Tomita et al., 2005; Miura et al., 2007) and can be applied to a transport model of aerosols and gases as a conventional atmospheric general circulation model (Suzuki et al., 2008; Niwa et al., 2011; Dai et al., 2014a, b; Goto, 2014). NICAM can also be employed for regional-scale simulations by adopting a stretched-grid system (Tomita, 2008a; Satoh et al., 2010). The stretched icosahedral grid was developed from a general grid transformation method, i.e., the Schmidt transformation method, for a horizontal grid system on a sphere. In the Schmidt transformation, the grid interval on a sphere lacks uniformity with a finer horizontal resolution close to the center of the target region. Tomita (2008a) showed that the Schmidt transformation minimizes potential errors involving the isotropy and homogeneity of the target region. The stretched-grid system can solve the main problems associated with commonly 
used regional models, which occur from artificial perturbations near boundary areas in cases where meteorological and aerosol fields are prescribed. In addition, the computational cost of the stretched-grid system is substantially lower than that of a global calculation under the same horizontal resolution in the target region. For example, when the globally uniform grid with a maximum horizontal resolution of $10 \mathrm{~km}$ is applied to the global simulation, the minimum required theoretical computational cost is 64-256 times higher than the cost of the stretched-grid system in this study. Compared to conventional regional models, the computational cost may increase because the stretched-grid system requires the calculation outside the target domain. Furthermore, the model framework of the stretched global model is identical to that of the uniformed global model without special modifications, whereas the model framework of regional models is usually different from that of global models. These advantages can facilitate additional developments for global simulations by testing a new scheme with minimal computational cost. Compared with general regional models, the stretched-grid system is more suitable for the future study, which aimed to extend its use to the global uniform high-resolution NICAMSPRINTARS.

In this study, we adopt the stretched-grid system to focus on the Kanto region, including Tokyo, using glevel-6 resolution and the stretched ratio of 100 (we call it NICAMg6str), which is the ratio of the largest horizontal grid spacing located on the opposite side of the earth from Tokyo to the smallest horizontal grid spacing near Tokyo. As a result, a minimum horizontal resolution of $11 \mathrm{~km}$ around the center $\left(140.00^{\circ} \mathrm{E}, 35.00^{\circ} \mathrm{N}\right)$ was used. NICAM implements comprehensive physical processes of radiation, boundary layer and cloud microphysics. The radiation transfer model is implemented in NICAM with the k-distribution radiation scheme MSTRN, which incorporates scattering, absorption and emissivity by aerosol and cloud particles as well as absorption by gaseous compounds (Nakajima et al., 2000; Sekiguchi and Nakajima, 2008). The vertical turbulent scheme comprises the level 2 scheme of turbulence closure by Mellor and Yamada (1974), Nakanishi and Niino (2004, 2009) and Noda et al. (2009). The cloud microphysics consist of the six-class single-moment bulk scheme (water vapor, cloud water, rain, cloud ice, snowflakes and graupel) (Tomita, 2008b). Based on our experience in previous studies, we did not employ cumulus parameterization in this study (e.g., Tomita et al., 2005; Sato et al., 2009; Nasuno, 2013). The topography used in this study is based on GTOPO30 (the horizontal resolution is 30 arc s, that is approximately $1 \mathrm{~km}$ ) courtesy of the US Geological Survey. The vertical coordinates system adopts Lorenz grid and $z^{*}$ (terrain-following) coordinates with the 40 layers of $z$ levels and a model top of $40 \mathrm{~km}$ in height (Satoh et al., 2008). The time step was set to $20 \mathrm{~s}$.

\subsection{SPRINTARS}

Based on the approach of Suzuki et al. (2008), the threedimensional aerosol-transport model - Spectral RadiationTransport Model for Aerosol Species (SPRINTARS; Takemura et al., 2000, 2002, 2005; Goto et al., 2011a, b, c) - was coupled to NICAM in this study. The SPRINTARS model calculates the mass mixing ratios of the primary tropospheric aerosols, i.e., carbonaceous aerosol (EC and OC, organic carbon), sulfate, soil dust, sea salt and the precursor gases of sulfate, namely, $\mathrm{SO}_{2}$ and dimethylsulfide (DMS). The aerosol module considers the following processes; emission, advection, diffusion, sulfur chemistry, wet deposition and dry deposition, including gravitational settling. For carbonaceous aerosols, the $50 \%$ mass of EC from fossil fuel sources is composed of externally mixed particles, whereas other carbonaceous particles are emitted and treated as internal mixtures of EC and $\mathrm{OC}$ (EC-OC internal mixture). Biogenic secondary organic aerosols (SOAs) from terpenes are treated but are greatly simplified by multiplying a conversion factor to the terpenes emission (Takemura, 2012). In addition, anthropogenic SOAs from toluene and xylene are disregarded in this study. The bulk mass concentrations of EC, OC, and sulfate are calculated by single-modal approach, which means that the SPRINTARS model does not explicitly treat aerosol dynamic processes such as coagulation and condensation. The particle size distribution of the dry particles are prescribed in a logarithmic normal size distributions with dry mode radii of $18,100,80$ and $69.5 \mathrm{~nm}$, for pure EC, EC-OC internal mixture, biogenic SOA and externally mixed sulfate, respectively (Goto et al., 2011a). The hygroscopicities, densities and refractive indices for the aerosols are set to the same values used by Takemura et al. (2002) and Goto et al. (2011a). The combinations of the pre-calculated cross sections of the extinction and simulated mixing ratios for each aerosol species provide the simulated aerosol extinction coefficient for each time step of the model (Takemura et al., 2002). The sulfur chemistry in SPRINTARS considers only three chemical reactions to form sulfate through gas-phase oxidation of $\mathrm{SO}_{2}$ by hydroxyl radical $(\mathrm{OH})$ and aqueous-phase oxidation by ozone and hydrogen peroxide. The large part of $\mathrm{SO}_{2}$ are emitted from fossil fuel combustion, biomass burning, and volcano eruption, whereas some of $\mathrm{SO}_{2}$ are formed from the oxidation of DMS, which is emitted naturally from marine phytoplanktons. The numerical solution in the oxidations adopts an approximation in a quasi first-order reaction using the same integrated time resolution as that of the dynamic core. The $\mathrm{pH}$ value in the aqueous-phase is fixed at 5.6, because the SPRINTARS model treats limited ions in the aqueous-phase (e.g., Takemura et al., 2000). The oxidant distributions $(\mathrm{OH}$, ozone and hydrogen peroxide) were offline provided by a chemical transport model. The atmospheric removal of aerosols in SPRINTARS includes wet (due to rainout and washout) and dry (due to turbulence and gravity) deposition processes, 
whereas those of $\mathrm{SO}_{2}$ only include rainout and dry deposition by turbulence. In the cloudy grid, the mass fractions of sulfate out of the cloud droplets to the mass of sulfate in the grid were fixed at 0.5 , whereas the fractions for $\mathrm{SO}_{2}$ were determined by Henry's law (Takemura et al., 2002). As for pure EC, EC-OC internal mixture, and biogenic SOA, the mass fractions were fixed at $0.1,0.3$, and 0.3 , respectively. Because the SPRINTARS model does not predict the mass mixing ratio of the chemical tracers inside the clouds, it assumes that the tracers inside the clouds are evaporated from the clouds at one time step. In this study, the particle mass concentrations for diameters less than $2.5 \mu \mathrm{m}$ (defined as $\mathrm{PM}_{2.5}$ ) are calculated by summing EC, organic matter by multiplying OC by 1.6 (Turpin and Lim, 2001), sulfate and ammonium aerosols. Because this model cannot directly predict ammonium compounds, it is assumed that all sulfate is the form of ammonium sulfate, so that their concentration was estimated by multiplying the mass concentration of sulfate by 0.27 , which is the molar ratio of ammonium ion to ammonium sulfate. The nitrate in this study is disregarded, primarily because the main objective in this study is modeling of sulfate as a representative secondary aerosols and secondly because the nitrate mass concentrations are lower than the sulfate ones with the target of August 2007 in Japan (Morino et al., 2010c).

\subsection{Design of the experiments}

The target period comprises one month in August 2007, in which an intensive measurement of aerosol chemical species was conducted under Project FAMIKA (Hasegawa et al., 2008; Fushimi et al., 2011). The $6 \mathrm{~h}$ meteorological fields (wind and temperature) were nudged above a height of $2 \mathrm{~km}$ using NCEP-FNL reanalysis data (http://rda.ucar.edu/ datasets/ds083.2/). The 1 day sea surface temperature was also nudged using the NCEP-FNL data. The initial conditions were prescribed by the NCEP-FNL data for the meteorological fields and the one and a half month spinup results of the Stretch-NICAM-SPRINTARS model for the aerosol fields, respectively.

The emission inventories of anthropogenic EC, OC and $\mathrm{SO}_{2}$ in this experiment were prepared by EAGrid2000 with a horizontal resolution of $1 \mathrm{~km}$ over Japan (Kannari et al., 2007), REAS version 2 with a horizontal resolution of $0.25^{\circ}$ over Asia (Kurokawa et al., 2013) and the AeroCom inventory with a horizontal resolution of $1^{\circ}$ over other areas of the world (Diehl et al., 2012). Because EAGrid2000 does not explicitly estimate $\mathrm{EC}$ and $\mathrm{OC}$ inventories, we estimated the inventories to be consistent with those from previous studies (Morino et al., 2010a, b; Chatani et al., 2011) by modifying the $\mathrm{PM}_{2.5}$ inventory of EAGrid2000 using scaling factors of $\mathrm{EC} / \mathrm{PM}_{2.5}$ and $\mathrm{OC} / \mathrm{PM}_{2.5}$ based on sources. These inventories of anthropogenic EC and $\mathrm{SO}_{2}$ in 2007 are described in Fig. 2. The emissions of $\mathrm{SO}_{2}$ from volcanoes in Japan, such as Miyakejima and Sakura-jima, were obtained from statistical reports (http://www.data.jma.go.jp/svd/vois/data/tokyo/
STOCK/monthly_v-act_doc/monthly_vact_2007.htm) by the Japan Meteorological Agency (JMA). In this study, the distributions of three-hourly averaged monthly oxidants $(\mathrm{OH}$, ozone and hydrogen peroxide) were derived from a global chemical transport model (CHASER) coupled to the Model for Interdisciplinary Research on Climate (MIROC), named MIROC-CHASER, with a spatial resolution of $2.8^{\circ}$ by $2.8^{\circ}$ (Sudo et al., 2002).

To evaluate model performances in the stretched-grid system, we also simulated NICAM-SPRINTARS with the globally uniformed grid simulation in glevel-6 resolution (the horizontal resolution is set to $110 \mathrm{~km}$, and we call it NICAMg6). Global-NICAM-SPRINTARS with relatively low resolution has been applied to aerosol simulations and well compared with in situ measurements and satellite remote sensing (Dai et al., 2014a; Goto, 2014). Apart from the NICAM-g6str simulation, in the NICAM-g6 simulation, the cloud physics apply both the prognostic Arakawa-Schubert-type cumulus convection scheme (Arakawa and Schubert, 1974) and the diagnostic large-scale clouds described by Le Treut and $\mathrm{Li}$ (1991). The large-scale cloud module is based on single moment bulk scheme for cloud mixing ratio. The precipitation rate is parameterized by Berry (1967). Except for the grid system and the horizontal resolution (which determines the module of the cloud physics), Global-NICAM-SPRINTARS was identical to Stretch-NICAM-SPRINTARS. Therefore, the comparison between NICAM-g6str and NICAM-g6 led to the clarification of impacts of the horizontal resolution on the aerosol distribution.

\subsection{Observation}

In this study, we focused on the aerosol chemical component of EC as the primary particle and sulfate as the secondary particle. To evaluate the model results over the Kanto region, we used observations of the surface mass concentrations of EC and sulfate in four cities under Project FAMIKA: Maebashi/Gunma $\left(139.10^{\circ} \mathrm{E}, 36.40^{\circ} \mathrm{N}\right)$, Kisai/Saitama $\left(139.56^{\circ} \mathrm{E}, 36.09^{\circ} \mathrm{N}\right)$, Komae/Tokyo $\left(139.58^{\circ} \mathrm{E}, 35.64^{\circ} \mathrm{N}\right)$ and Tsukuba/Ibaraki $\left(140.12^{\circ} \mathrm{E}, 36.05^{\circ} \mathrm{N}\right)$. The EC particles in $\mathrm{PM}_{2.5}$ were collected every $6 \mathrm{~h}$ with quartz fiber filters and analyzed with the thermal/optical method according to the IMPROVE protocol (Chow et al., 2001). The sulfate particles in $\mathrm{PM}_{2.5}$ were also collected every $6 \mathrm{~h}$ with Teflon filters and analyzed by ion chromatography. In addition to the limited FAMIKA data set, we utilized measurements taken by the EANET (Acid Deposition Monitoring Network in East Asia; http://www.eanet.asia/index.html) and the fourth national survey report of acid rain over Japan in the 2007 fiscal year (http://tenbou.nies.go.jp/science/institute/region/ journal/JELA_3403041_2009.pdf) to assess the monthly mean concentrations of sulfate and $\mathrm{SO}_{2}$ at Japanese and Korean sites. We also obtained Chinese measurements by Zhang et al. (2012), as part of the Chinese Meteorological Adminis- 
(a) EC inventory in 2007

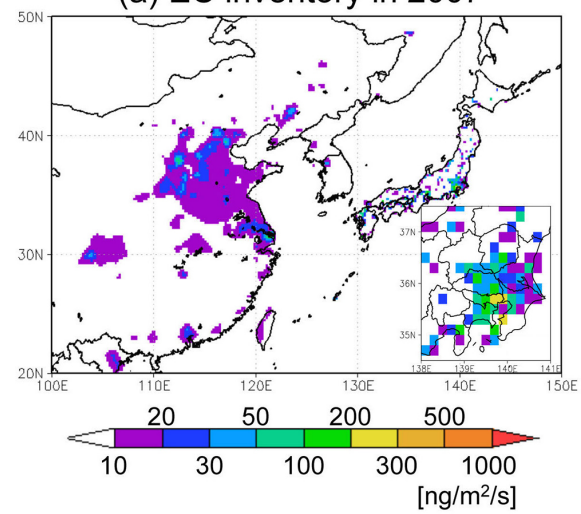

(b) $\mathrm{SO}_{2}$ inventory in 2007

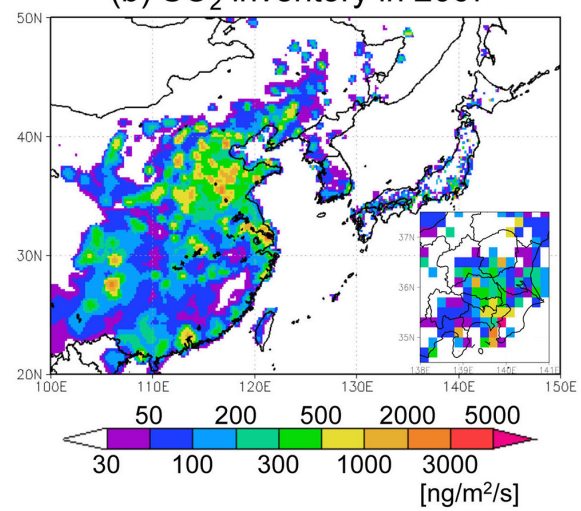

Figure 2. (a) $\mathrm{EC}$ and (b) $\mathrm{SO}_{2}$ emission inventories in 2007.

Table 1. Statistical values (averages of the observation and simulations, correlation coefficient $R$ and root mean square error RMSE) for meteorological fields using the simulations (NICAM-g6str and NICAM-g6) and observations at seven sites during the same period, as shown in Figs. 4 to 7.

\begin{tabular}{|c|c|c|c|c|c|c|c|c|}
\hline & & Yokohama & Chiba & Tsuchiura & Adachi & Maebashi & Machida & Kisai \\
\hline & & \multicolumn{7}{|c|}{ Temperature } \\
\hline \multirow{3}{*}{$\begin{array}{l}\text { Average }\left({ }^{\circ} \mathrm{C}\right) \text { and difference } \\
\left({ }^{\circ} \mathrm{C}\right) \text { (vs. observation) } \\
\text { in bracket }\end{array}$} & Observation & 27.9 & 30.1 & 28.1 & 29.7 & 29.1 & 29.1 & 27.9 \\
\hline & NICAM-g6str & $26.9(-1.1)$ & $28.3(-1.8)$ & $28.3(0.2)$ & $27.3(-2.3)$ & $25.5(-3.6)$ & $25.9(-3.2)$ & $25.8(-2.2)$ \\
\hline & NICAM-g6 & $25.5(-2.4)$ & $26.2(-3.9)$ & $25.7(-2.4)$ & $25.5(-4.1)$ & $23.9(-5.2)$ & $25.5(-3.6)$ & $23.9(-4.0)$ \\
\hline \multirow{2}{*}{$R$} & NICAM-g6str & 0.74 & 0.85 & 0.84 & 0.81 & 0.79 & 0.74 & 0.80 \\
\hline & NICAM-g6 & 0.76 & 0.67 & 0.79 & 0.78 & 0.71 & 0.77 & 0.75 \\
\hline \multirow{2}{*}{$\operatorname{RMSE}\left({ }^{\circ} \mathrm{C}\right)$} & NICAM-g6str & 1.9 & 2.3 & 1.9 & 3.0 & 4.3 & 3.9 & 3.0 \\
\hline & NICAM-g6 & 2.8 & 4.4 & 3.1 & 4.6 & 5.8 & 4.0 & 4.6 \\
\hline \multirow{4}{*}{$\begin{array}{l}\text { Average }(\%) \text { and difference } \\
(\%) \text { (vs. observation) } \\
\text { in bracket }\end{array}$} & & \multicolumn{7}{|c|}{ RH } \\
\hline & Observation & 73.5 & 79.0 & 73.3 & 75.4 & 73.7 & 75.9 & 71.4 \\
\hline & NICAM-g6str & $83.6(10.0)$ & $77.5(-1.5)$ & $76.4(3.0)$ & 77.9 (2.5) & $82.7(9.0)$ & 82.5 (6.6) & $81.6(10.1)$ \\
\hline & NICAM-g6 & $92.2(18.6)$ & $92.4(13.4)$ & $93.4(20.0)$ & $92.2(16.8)$ & $95.5(21.9)$ & $92.2(16.3)$ & $95.5(24.1)$ \\
\hline \multirow{2}{*}{$R$} & NICAM-g6str & 0.64 & 0.68 & 0.69 & 0.72 & 0.72 & 0.72 & 0.81 \\
\hline & NICAM-g6 & 0.73 & 0.59 & 0.79 & 0.82 & 0.71 & 0.74 & 0.76 \\
\hline \multirow{2}{*}{ RMSE (\%) } & NICAM-g6str & 12.7 & 8.9 & 11.0 & 10.1 & 14.6 & 12.9 & 13.3 \\
\hline & NICAM-g6 & 19.5 & 16.2 & 22.4 & 19.8 & 25.5 & 20.1 & 26.3 \\
\hline \multirow{4}{*}{$\begin{array}{l}\text { Average }\left(\mathrm{m} \mathrm{s}^{-1}\right) \text { and difference } \\
\left(\mathrm{m} \mathrm{s}^{-1}\right)(\mathrm{vs} \text {. observation }) \\
\text { in bracket }\end{array}$} & & \multicolumn{7}{|c|}{ Wind speed } \\
\hline & Observation & 2.9 & 2.6 & 1.6 & 2.6 & 1.2 & 2.7 & 1.9 \\
\hline & NICAM-g6str & $4.2(1.3)$ & $3.8(1.1)$ & $3.1(1.4)$ & $3.4(0.9)$ & $3.1(1.9)$ & $3.0(0.3)$ & $2.7(0.8)$ \\
\hline & NICAM-g6 & $3.7(0.7)$ & $5.0(2.4)$ & $1.0(-0.7)$ & $3.7(1.1)$ & $0.9(-0.4)$ & $3.7(1.0)$ & $0.9(-1.0)$ \\
\hline \multirow{2}{*}{$R$} & NICAM-g6str & 0.72 & 0.41 & 0.65 & 0.51 & 0.19 & 0.59 & 0.16 \\
\hline & NICAM-g6 & 0.64 & 0.43 & 0.38 & 0.47 & 0.12 & 0.53 & 0.04 \\
\hline \multirow{2}{*}{$\operatorname{RMSE}\left(\mathrm{ms}^{-1}\right)$} & NICAM-g6str & 1.9 & 2.0 & 1.8 & 1.7 & 2.3 & 1.3 & 1.7 \\
\hline & NICAM-g6 & 1.4 & 3.0 & 1.2 & 1.7 & 0.7 & 1.7 & 1.4 \\
\hline
\end{tabular}

tration Atmosphere Watch Network (CAWNET). To validate the concentration of $\mathrm{SO}_{2}$ for the Kanto region, we accessed monitoring stations operated by Japanese and local governments.
In the validation of the meteorological fields simulated by NICAM-g6str and NICAM-g6, we used meteorological fields (wind and temperature) reanalyzed by NCEP-FNL over East Asia. In the Kanto region, we obtained measurements for the meteorological parameters (temperature, rel- 
ative humidity (RH) and wind) at or near the seven sites of Project FAMIKA and additional cities: Tsuchiura/Ibaraki $\left(140.20^{\circ} \mathrm{E}, 36.07^{\circ} \mathrm{N}\right)$, which is the city nearest to Tsukuba; Yokohama/Kanagawa $\left(139.64^{\circ} \mathrm{E}, 35.45^{\circ} \mathrm{N}\right)$; Chiba/Chiba $\left(140.12^{\circ} \mathrm{E}, 35.62^{\circ} \mathrm{N}\right)$; Adachi/Tokyo $\left(139.82^{\circ} \mathrm{E}, 35.77^{\circ} \mathrm{N}\right)$; and Machida/Tokyo $\left(139.43^{\circ} \mathrm{E}, 35.53^{\circ} \mathrm{N}\right)$, which is the city nearest to Komae, as shown in Fig. 1b. For precipitation, we used a measurement taken by the Automated Meteorological Data Acquisition System (AMeDAS) at 21 sites over Japan including the following 10 Kanto's sites: Yokohama; Chiba; Tsukuba; Tokyo, which is near Adachi; Maebashi; Huchu, which is near Machida; Konosu, which is near Kisai; Abiko $\left(140.11^{\circ} \mathrm{E}, 35.60^{\circ} \mathrm{N}\right)$; Saitama $\left(139.59^{\circ} \mathrm{E}, 35.88^{\circ} \mathrm{N}\right)$; and Nerima $\left(139.59^{\circ} \mathrm{E}, 35.74^{\circ} \mathrm{N}\right.$ ) (Fig. 1). To evaluate the spatial patterns of the precipitation obtained by NICAM-g6str and NICAM-g6, we used the quantities of the monthly mean precipitation around Japan that were derived from the Global Satellite Mapping of Precipitation (GSMaP; Okamoto et al., 2005; Kubota et al., 2007; Aonashi et al., 2009; Ushio et al., 2009) and the Meso Scale Model (MSM) developed by the JMA for rain forecast (Saito et al., 2006). The results by MSM are generally higher accurate than those in GSMaP, although the covering area in MSM is limited around Japan.

To evaluate the quantities of the total aerosol amounts, such as $\mathrm{PM}_{2.5}$, we compared the simulated $\mathrm{PM}_{2.5}$ concentrations with the observations at the 18 sites including the FAMIKA sites and other monitoring stations operated by the Japanese and local governments (Fig. 1). The $\mathrm{PM}_{2.5}$ concentrations were continuously observed using tapered element oscillating microbalance (TEOM) with Series 1400a Ambient Particulate Monitor. The instruments are controlled under the temperature of $50{ }^{\circ} \mathrm{C}$, to minimize the influence of change in the ambient temperature and RH. However, it includes large uncertain due to the difficulty in completely eliminating the water content attached to aerosols and lacks the calibration of the instrument in some of the sites. Nevertheless, the observed $\mathrm{PM}_{2.5}$ concentrations with hourly time resolution were still useful for validating the model results.

In Tsukuba and Chiba, light detection and ranging (LIDAR) measurements operated by the National Institute for Environmental Studies (NIES) of Japan were also available (Sugimoto et al., 2003; Shimizu et al., 2004). The LIDAR unit measured vertical profiles of the backscattering intensity at 532 and $1064 \mathrm{~nm}$ and the depolarization ratio at $532 \mathrm{~nm}$. The backscattering intensity was converted to the extinction coefficient, and the depolarization ratio distinguished the extinction between spherical and non-spherical particles. In this study, we only used vertical profiles of the extinction for spherical particles. A detailed algorithm was provided by Sugimoto et al. (2003) and Shimizu et al. (2004).

\section{Validation of Stretch-NICAM-SPRINTARS}

\subsection{Meteorological fields}

So far, the stretched-grid system was mainly applied to the simulations of tropical cyclones or tropical convective clouds with small domains over oceans for the short-term period (less than several days) (e.g., Satoh et al., 2010; Arakane et al., 2014). In this study, we focused on the air pollution around Japan (for the longer period). Therefore, we first focused on the general circulation of the basic meteorological fields over the large domain, which can affect the air pollution over Japan. Figure 3 shows temperature and winds near the surface and the model height of approximately $5 \mathrm{~km}$ over Asia region $\left(100-170^{\circ} \mathrm{E}, 10-50^{\circ} \mathrm{N}\right)$. In August, North Pacific High (or Ogasawasa High) mainly brings clear weather around Japan. A frequency of the precipitation is usually limited, but a total amount of the monthly mean precipitation is not small, because of typhoons and shower rain. In the focusing region, the general meteorological fields simulated by NICAM-g6str and NICAM-g6 are comparable to those obtained by NCEP-FNL. The absolute biases in the temperature between NICAM-g6str and NCEP-FNL or between NICAM-g6 and NCEP-FNL are within $1.5^{\circ} \mathrm{C}$ at the surface and the height of $5 \mathrm{~km}$. Around the Japanese Alps, however, the NICAM-g6str-simulated temperature is lower than the NCEP-FNL-estimated one by at most $2.5^{\circ} \mathrm{C}$, because of the differences in the resolved topography due to the different spatial resolution between NICAM-g6str and NCEP-FNL. As for wind, western winds over the northeastern part of Japan in both NICAM-g6str and NICAM-g6 are stronger compared to those in NCEP-FNL. With the exception of this bias, the performances of both NICAM-g6str and NICAM-g6 are good. Therefore, it is concluded that the stretched-grid systems do not affect the general circulations under the nudging technique in this study.

To evaluate the model performances of the six-hourly mean concentrations of aerosol chemical species and $\mathrm{SO}_{2}$ over the main target region, i.e., Kanto area, we used the six-hourly instant observations of temperature, $\mathrm{RH}$, wind and precipitation at each station over the Kanto area shown in Fig. 1. The results and summary are shown in Figs. 4 to 7 and Table 1. The NICAM-g6 results, especially in terms of diurnal variations, tend to be far from the observations compared to the NICAM-g6str results, because NICAM-g6, with the horizontal resolution of approximately $100 \mathrm{~km}$, does not fully resolve the topology over the Kanto area. Figure 4 illustrates the temporal variations of temperature at a height of $2 \mathrm{~m}$. The temporal variations in the NICAM-g6str-simulated temperature are generally comparable to those in the observed temperatures with root-mean-square-error (RMSE) values of less than $3{ }^{\circ} \mathrm{C}$, with the exception of the results obtained for Maebashi and Machida. At these two sites, the mean values of the NICAM-g6str-simulated temperatures are lower than those of the observed temperatures by a maximum 

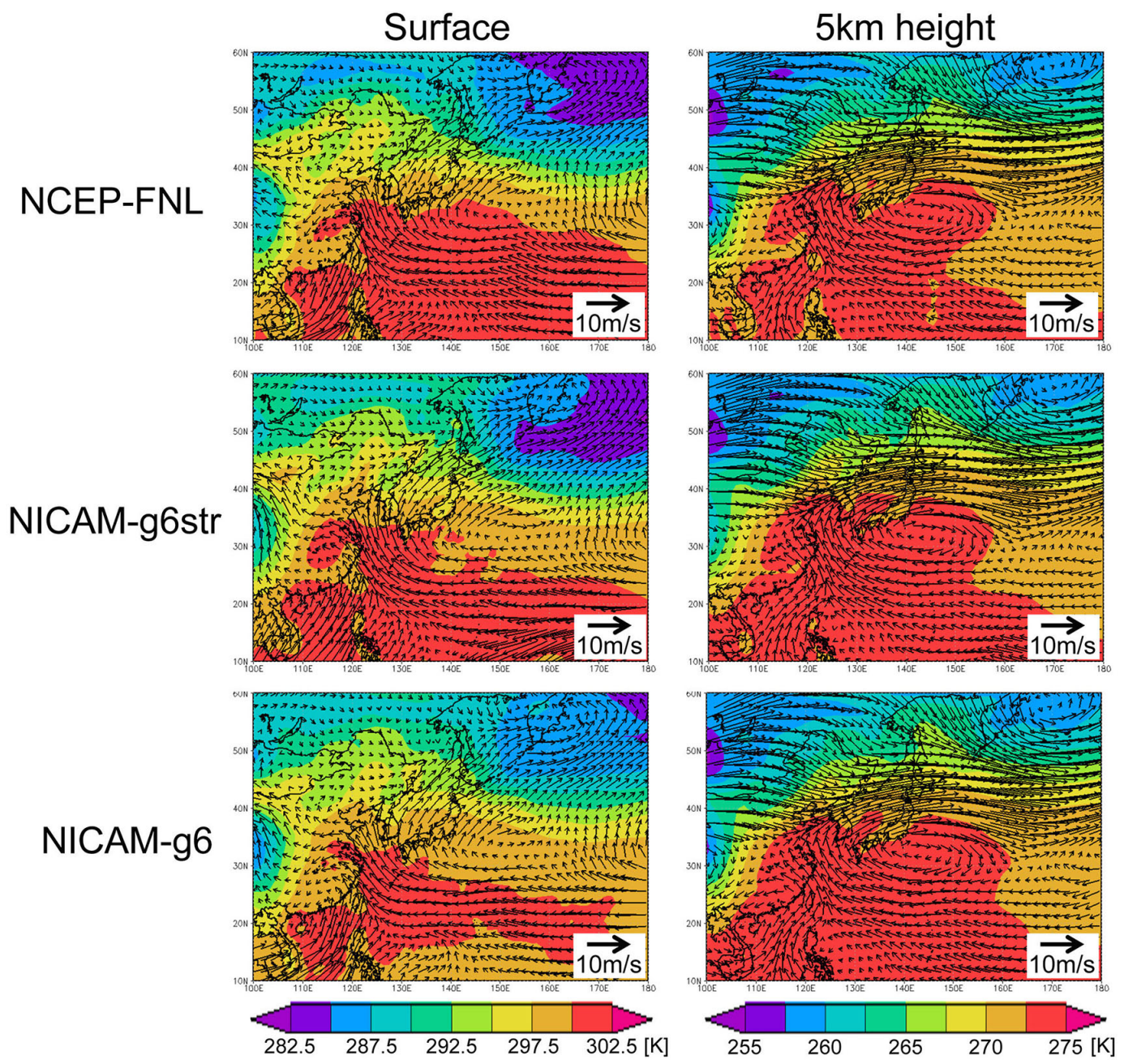

Figure 3. Horizontal distributions of temperature and winds in August averages at the surface and the model height of approximately $5 \mathrm{~km}$ over the Asia region using reanalysis data from NCEP-FNL, simulation by NICAM-g6str, and simulation by NICAM-g6.

of $3.6^{\circ} \mathrm{C}$. The correlation coefficients $(R)$ between NICAMg6str and the observation range from 0.7 to 0.9 , whereas the $R$ between NICAM-g6 and the observation range from 0.7 to 0.8 , as shown in Table 1 . Figure 5 shows the temporal variations in $\mathrm{RH}$ at a height of $2 \mathrm{~m}$. The temporal variations in the NICAM-g6str-simulated RH are similar to the observations, with the RMSEs in the range of 10-15\%. In contrast, the NICAM-g6-simulated RH is overestimated compared to the observations, with the RMSEs in the range of 16-26\%. The $R$ values of RH between the simulation (both NICAM-g6str and NICAM-g6) and observations are approximately $0.6-0.8$ (Table 1).

The temporal variations in the wind direction and speed simulated by NICAM-g6str are compared with the observations in Figs. 6 and 7. Near the southern part of the Kanto area (Yokohama, Tsuchiura, Adachi and Machida), with the exception of Chiba, the NICAM-g6str-simulated wind direction is generally comparable to the observations, with a slight overestimation of the both NICAM-g6str and NICAM- g6 simulated wind speed compared with the observations. At these four sites, the $R$ and RMSE values in NICAMg6str range from approximately 0.5 to 0.7 and from approximately 1.7 to $2.3 \mathrm{~m} \mathrm{~s}^{-1}$, respectively. In Chiba located near the ocean, the $R$ value of wind speed between NICAMg6str and the observation is 0.41 , whereas the NICAM-g6strsimulated wind directions generally agree with the observations. Conversely, at Maebashi and Kisai, the daily variations in the both NICAM-g6str and NICAM-g6 simulated wind directions differ significantly from those in the observations, in which the southern winds and northern winds frequently occur during the day and night, respectively, for example, during 5-12 August. At these two sites, the NICAMg6-simulated wind direction and speed is not closer to the observations compared to those obtained by NICAM-g6str. The $R$ value for wind speed between the NICAM-g6str and the observations at these sites is estimated to be approximately 0.2 . The observed southeasterly wind is long sea breeze toward Maebashi Plateau surrounded on three sides by moun- 

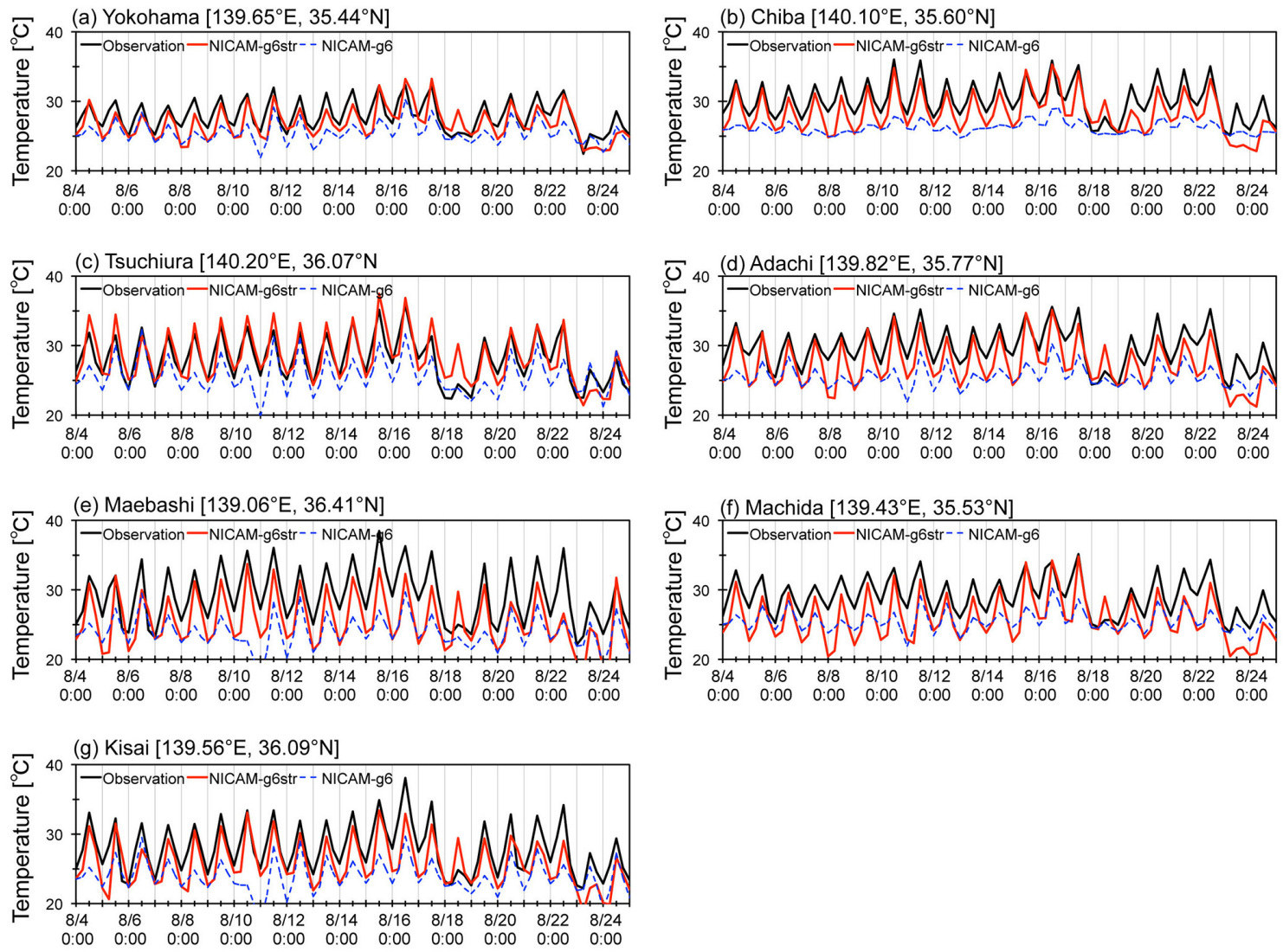

Figure 4. Temporal variations in the NICAM-g6str and NICAM-g6 simulated and observed air temperature for a height of $2 \mathrm{~m}$ at (a) Yokohama, (b) Chiba, (c) Tsuchiura, (d) Adachi, (e) Maebashi, (f) Machida and (g) Kisai in August 2007.

tains around Maebashi. The observed winds are caused by daytime meso-scale thermal lows developed over the central Japan covering the Japanese Alps (Kuwagata and Sumioka, 1991). The Japanese Alps with the highest terrain in Japan can affect the local meteorological fields even around 100 $200 \mathrm{~km}$ away (Kitada et al., 1998). Therefore, it suggests that the horizontal resolution in this study using NICAM-g6str (10 km over the Kanto area) does not fully resolve the complex terrains of the Japanese Alps and the Maebashi plateau. Therefore, it suggests that it is inadequate to simulate the wind patterns and the diurnal transitions near high mountains around the Kanto area, whereas it is adequate for simulating them around the center of the Kanto area.

Figures 8-10 show comparisons of NICAM-g6str- and NICAM-g6-simulated precipitation with the observations. Figure 8 compares the simulated precipitation with the MSM and GSMaP derived results. During the early August 2007, mainly due to passing of a typhoon over the western Japan, Okinawa, and Korea, the August mean precipitation in the western Japan is larger than that in the eastern Japan, especially the Kanto area. The monthly mean precipitation is estimated to be more than $200 \mathrm{~mm}_{\text {month }}{ }^{-1}$ over the western Japan, whereas that is estimated to be less than
$50 \mathrm{~mm}$ month $^{-1}$ over the eastern Japan. The horizontal patterns of the precipitation obtained by NICAM-g6str in East China Sea, Sea of Japan near the Japan coast, and Korea are closer to those derived from MSM and GSMaP than those obtained by NICAM-g6. In the Kanto area, however, the NICAM-g6str-simulated precipitation with the range of 50-200 mm month ${ }^{-1}$ is overestimated compared to the MSM and GSMaP results. The NICAM-g6-simulated precipitation over the Kanto area with the range of 100-200 mm month ${ }^{-1}$ is also much overestimated. In Fig. 9 showing the temporal variations in the amount of precipitation per day at 21 Japanese sites, the observed precipitation is extremely limited during 7-19 August in the Kanto area. In other regions, the magnitude of the precipitation is strong, although the precipitation is sporadic. In terms of the frequency of the precipitation, the NICAM-g6str performance is better than the NICAM-g6 one. Figure 10 illustrates the predictive value of daily precipitation, defined as the ratio of the number of days where the model correctly predicts the weather (less than $1 \mathrm{mmday}^{-1}$ or more than $1 \mathrm{mmday}^{-1}$ ) to the number of the whole days. In the NICAM-g6str results, the predictive values at most of the sites over the Kanto area and four sites over the non-Kanto area such as Nagoya and Osaka 

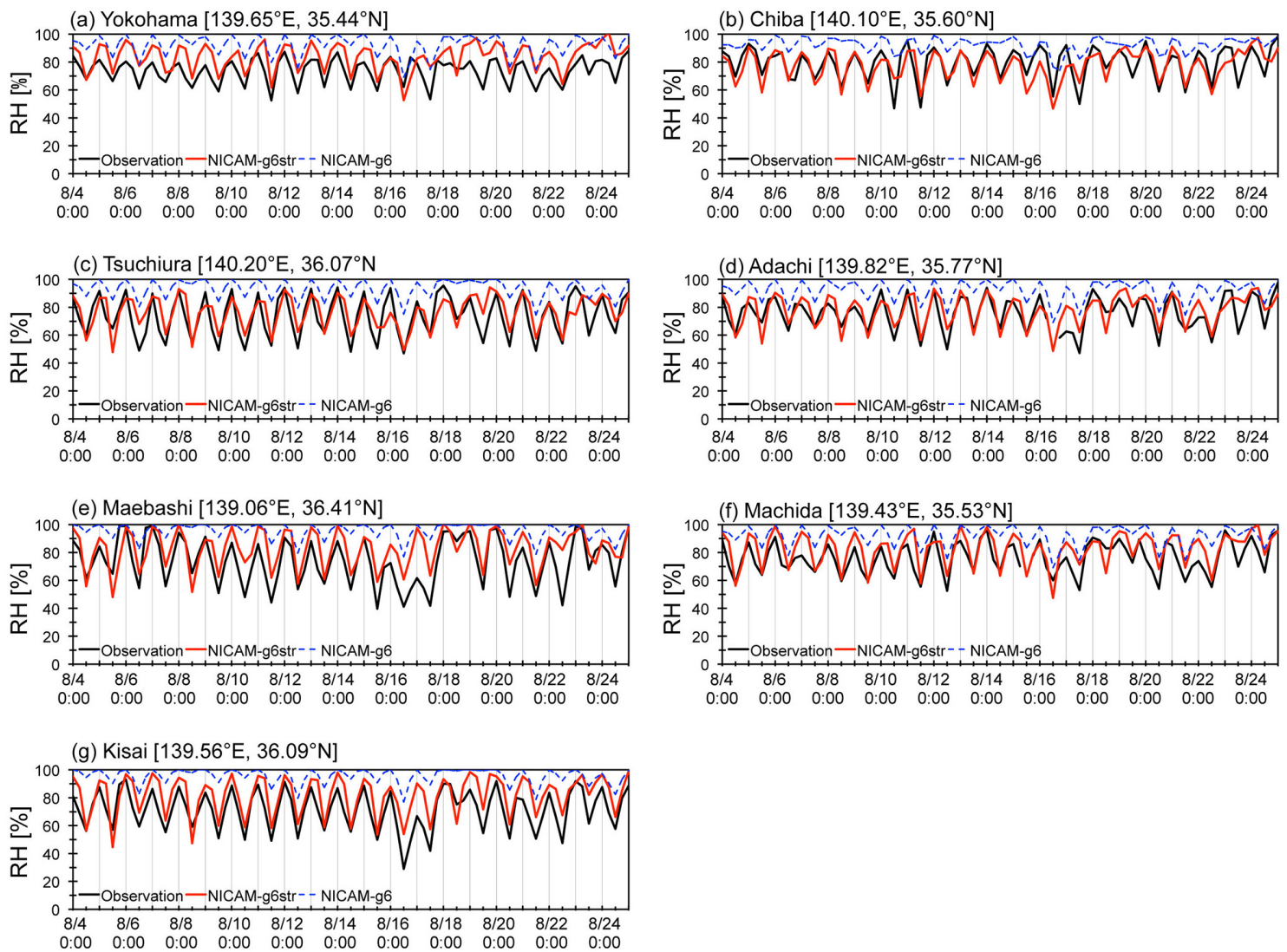

Figure 5. Same as Fig. 4 but for relative humidity (RH).

are calculated to be more than $85 \%$. The predictive values obtained by NICAM-g6str are mostly higher than those obtained by NICAM-g6. During the rainy days such as 20, 22 and 23 August over the Kanto area, both NICAM-g6str and NICAM-g6 capture the precipitation, whereas NICAM-g6str reproduces greater amounts of the precipitation and NICAMg6 reproduces longer periods and larger areas compared to the observations. NICAM-g6str does not always capture a sudden shower, as general meteorological models have difficulties in predicting this type of precipitation system (e.g., Kawabata et al., 2011). To increase the accuracy of such precipitation, more sophisticated cloud-microphysics model, e.g., NICAM-NDW6 model proposed by Seiki and Nakajima (2014) based on the double-moment bulk scheme with six water categories, may be required. In the western Japan, during the rainy days, e.g., 22-23 August, both NICAMg6str and NICAM-g6 usually capture large-scaled precipitation (Fig. 9). Overall, NICAM-g6str usually reproduces the observed weather in the target regions and periods, whereas NICAM-g6 does not capture general features such as the sporadic precipitation.

\subsection{Aerosol fields}

\subsubsection{Evaluation of chemical species}

Figures 11, 12, and 13 illustrate the temporal variations in the surface $\mathrm{EC}$, sulfate, and $\mathrm{SO}_{2}$ concentrations at the four stations (Maebashi, Kisai, Komae and Tsukuba) in the Kanto area using the simulations and the measurements. The simulations include NICAM-g6str, NICAM-g6, and the Community Multiscale Air Quality (CMAQ) driven by the Weather Research and Forecasting (WRF) model named WRF-CMAQ shown by their Figs. 5 and 6 of Shimadera et al. (2013). Shimadera et al. (2013) calculated the WRFCMAQ with a horizontal resolution of $5 \mathrm{~km}$ and an emission inventory that is similar to that in the present study. Table 2 summarizes the statistical parameters for the concentrations of $\mathrm{EC}$, sulfate, and $\mathrm{SO}_{2}$. The temporal variation and the average of EC simulated by NICAM-g6str are better agreement with the observations obtained for Komae than those simulated by NICAM-g6 (Fig. 11c). However, the averages of both NICAM-g6str and NICAM-g6 simulated EC concentrations at the other sites are much underestimated compared to the observations (Table 2). For Tsukuba shown in Fig. 11d, both the NICAM-g6str and NICAM-g6 simulated EC concentrations tend to be underestimated compared with the ob- 

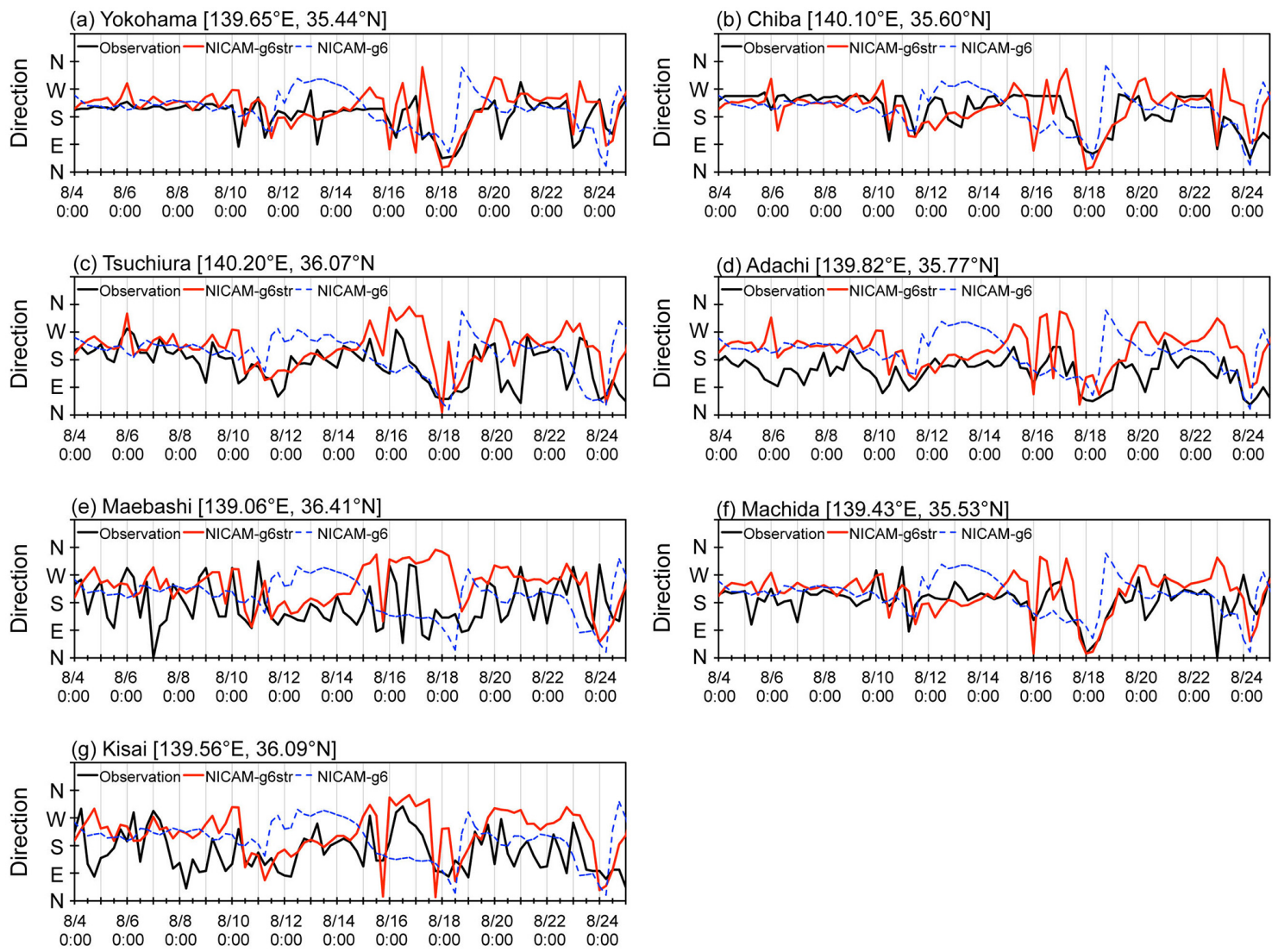

Figure 6. Same as Fig. 4 but for wind direction.

served concentrations, especially during the daytime, even though the temporal variation of EC obtained by NICAMg6str is closer to the observed one compared to those obtained by NICAM-g6. At Maebashi and Kisai, the temporal variation and the averages of EC obtained by NICAMg6 are also underestimated compared with the observations by a factor of three to five. NICAM-g6str tends to have daily maximums of EC concentrations during the morning time, whereas NICAM-g6 tends to have daily maximums during the nighttime. The temporal variations of NICAMg6str-simulated EC concentrations are generally comparable to those by WRF-CMAQ shown in Fig. 11 and their Fig. 3 of Chatani et al. (2014), with the exception of the results at Maebashi and Kisai where the EC concentrations obtained by NICAM-g6str are smaller than those obtained by WRFCMAQ. At these sties, the difference in the EC concentrations between NICAM-g6str and WRF-CMAQ is probably caused by the difference in the horizontal resolution, which is most likely critical for properly simulating the air pollution delivered by the meteorological wind fields from the center of the Kanto region (Kusaka and Hayami, 2006). Table 2 also shows that the $R$ obtained by NICAM-g6str at all sites are high or moderate, with the exception of Maebashi, whereas those obtained by NICAM-g6 and CMAQ are low. At most sites, the EC concentrations obtained by WRFCMAQ shown in Fig. 11, and WRF-CMAQ illustrated by Morino et al. (2010a, b) and Chatani et al. (2014), NICAMg6str, and NICAM-g6 are also underestimated compared to the observations with the larger values of RSME. The underestimation of EC concentrations is investigated by sensitivity tests of the EC emission inventory in Sect. 3.2.2.

At the same four sites, simulated sulfur components (sulfate and $\mathrm{SO}_{2}$ ) are compared with the observations in Figs. 12 and 13. The observed $\mathrm{SO}_{2}$ represents the ensemble results of monitoring stations operated by Japanese and local governments around each FAMIKA site. The mean differences in the sulfate mass concentrations between NICAM-g6str and the observations are within approximately $10 \%$ at Maebashi and Tsukuba, approximately $-30 \%$ at Komae, and approximately $+40 \%$ at Kisai. At all sites, the temporal variations of the NICAM-g6str-simulated sulfate concentrations are generally comparable to those obtained by the observations and WRF-CMAQ shown in Fig. 12 (i.e., Fig. 6 of Shimadera et al., 2013) and illustrated in Fig. 3 of Morino et al. (2010a), whereas the differences in the sulfate concentrations between NICAM-g6str and the observations are somewhat greater on 7 and 8 August at Maebashi where the performance of NICAM-g6str is relatively poor, mainly due to the inade- 

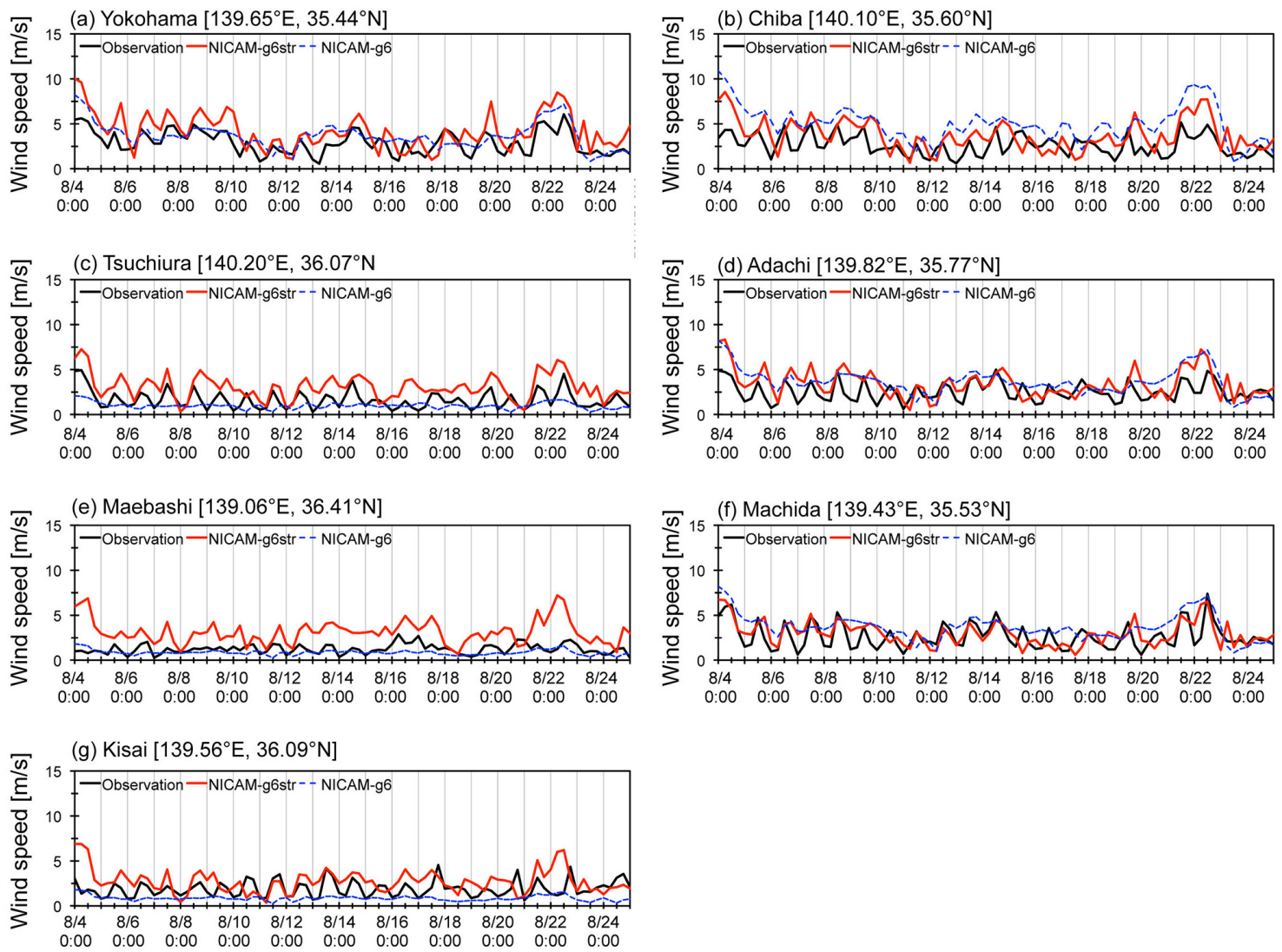

Figure 7. Same as Fig. 4 but for wind speed.

(a) NICAM-g6str

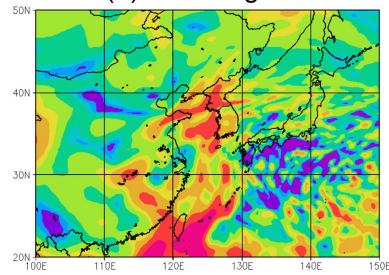

(c) MSM (by JMA)

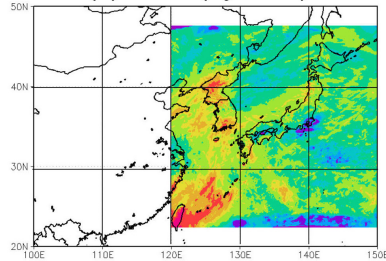

(d) GSMaP (multi-satellite)
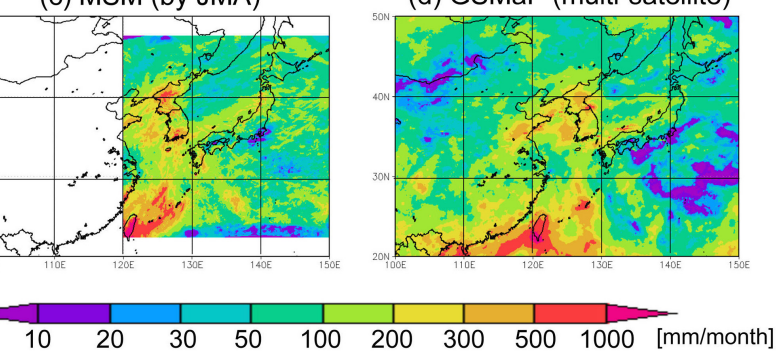

Figure 8. Horizontal distributions of precipitation in August averages derived from (a) simulation by NICAM-g6str, (b) simulation by NICAM-g6, (c) reanalysis data from MSM by JMA and (d) reanalysis data from GSMaP. quate horizontal resolution to reproduce the observed meteorological fields, as shown in Sect. 3.1. The use of the prescribed distributions of three-hourly averaged monthly oxidants may partly cause the discrepancy of the hourly variations of the sulfate between NICAM-g6str and the observations. The $R$ obtained by all the models (NICAM-g6str, NICAM-g6, and WRF-CMAQ) is acceptable at most sites, with the exception of NICAM-g6str at Maebashi and WRFCMAQ at Kisai. The RMSEs obtained by all the models are smaller at Komae and Tsukuba than those at Maebashi and Kisai. The six-hourly variations of the sulfate obtained by WRF-CMAQ are sometimes missed by NICAM-g6str, partly due to the use of the prescribed oxidants. Even though NICAM-g6 reproduces the synoptic cycle of the observed sulfate, it has difficulties in simulating the diurnal cycle of the observed and NICAM-g6str-simulated sulfate, as shown in the results of EC by Fig. 11. The averages of the sulfate concentrations obtained by NICAM-g6 tend to be smaller than those by NICAM-g6str and the observations. The possible impacts of the prescribed oxidant on the sulfate concentrations are investigated in Sect. 3.2.2.

In Fig. 13, NICAM-g6str and NICAM-g6 simulated $\mathrm{SO}_{2}$ concentrations are compared by the observations. In the previous studies, the comparison in $\mathrm{SO}_{2}$ concentrations between 

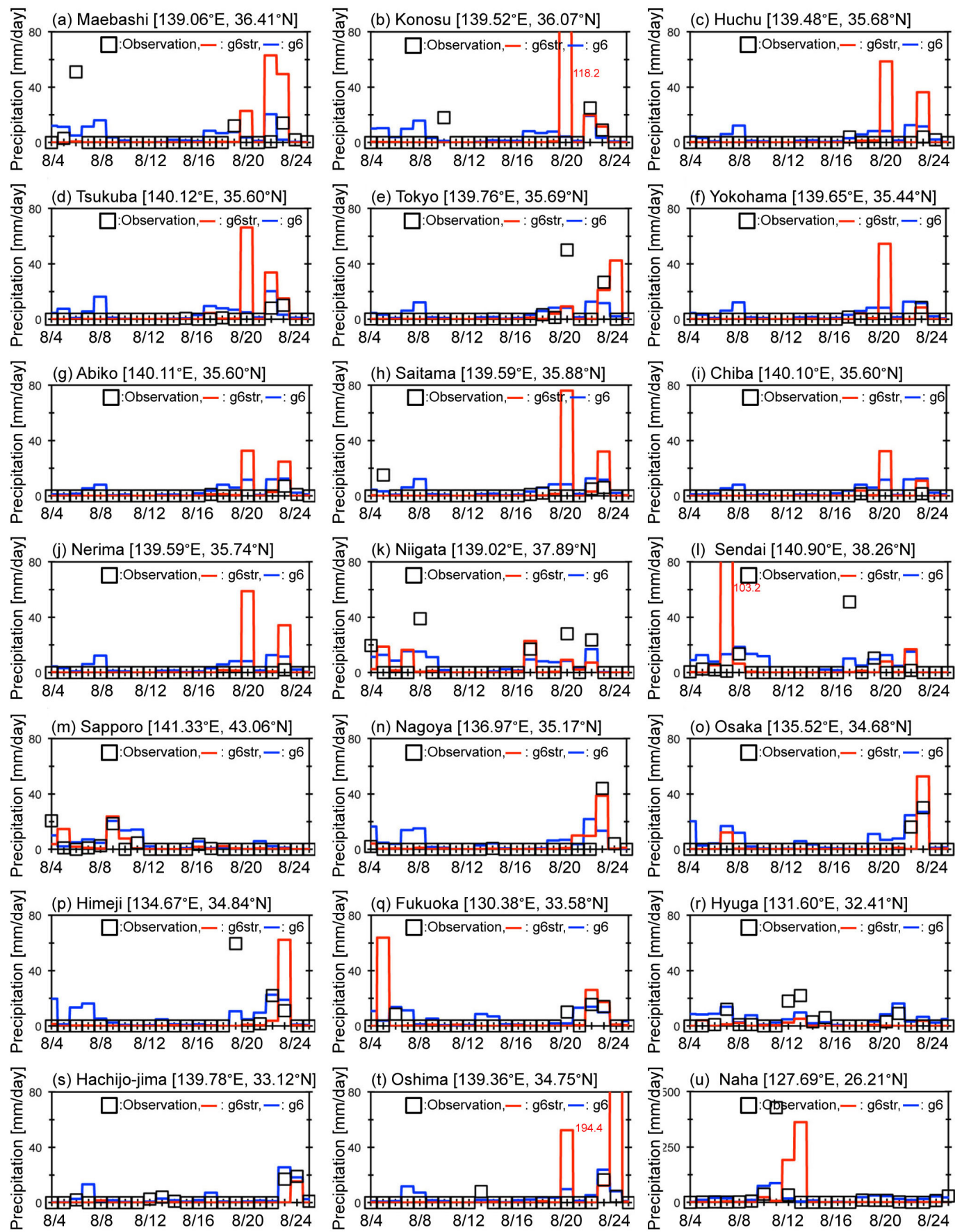

Figure 9. Temporal variations in the NICAM-g6str and NICAM-g6 simulated and observed precipitation amounts at 21 Japanese sites in August 2007. The comparison includes 10 sites in the Kanto area, (a) Maebashi, (b) Konosu, (c) Huchu, (d) Tsukuba, (e) Tokyo, (f) Yokohama, (g) Abiko, (h) Saitama, (i) Chiba, and (j) Nerima, 3 sites in northern Japan, (k) Niigata, (l) Sendai, and (m) Sapporo, 5 sites in western Japan, (n) Nagoya, (o) Osaka, (p) Himeji, (q) Fukuoka, and (r) Hyuga, and 3 remote islands, (s) Hachijo-jima, (t) Oshima, and (u) Naha.

the simulation and observation was very limited, with the exception of their Fig. 4 of Morino et al. (2010b), which showed large differences in the $\mathrm{SO}_{2}$ concentrations between WRF-CMAQ and the observations by more than a factor of two. The $R$ between NICAM-g6str and the obser- vations are low, with the exception of Komae $(R=0.62)$, but are approximately within the range obtained by WRFCMAQ in Morino et al. (2010b). The differences in the mean $\mathrm{SO}_{2}$ concentrations between NICAM-g6str and the observations and between NICAM-g6 and the observations are 


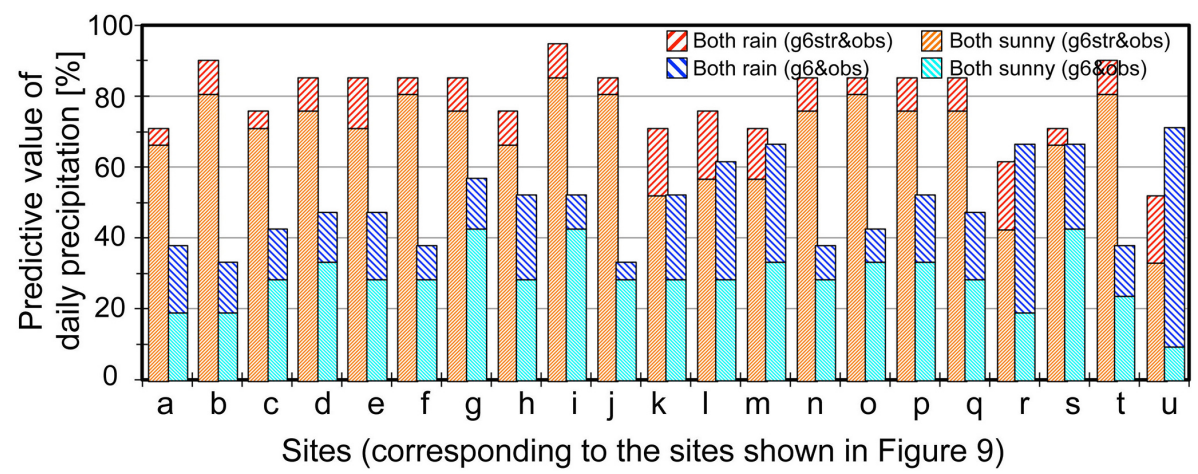

Figure 10. Predictive values of daily precipitation using the NICAM-g6str and NICAM-g6 simulations and the AMeDAS measurements during August 2007 at the sites defined at Fig. 9, in units of percentage.

Table 2. Statistical values (averages of the observation and simulations, correlation coefficient $R$ and root mean square error RMSE) for EC, sulfate, and $\mathrm{SO}_{2}$ concentrations by the simulations (NICAM-g6str, NICAM-g6, and WRF-CMAQ) and the observations at four FAMIKA sites during the period from 6 to 11 August. The WRF-CMAQ results are given by Shimadera et al. (2013).

\begin{tabular}{|c|c|c|c|c|c|}
\hline & & Maebashi & Kisai & Komae & Tsukuba \\
\hline & & \multicolumn{4}{|c|}{$\mathrm{EC}$} \\
\hline \multirow{4}{*}{$\begin{array}{l}\text { Average }\left(\mu \mathrm{g} \mathrm{m}^{3}\right) \text { and difference }(\%) \\
\text { (vs. observation) in brackets }\end{array}$} & Observation & 2.85 & 2.75 & 1.23 & 2.20 \\
\hline & NICAM-g6str & $0.39(-86)$ & $0.60(-78)$ & $1.10(-10)$ & $0.73(-67)$ \\
\hline & NICAM-g6 & $0.52(-82)$ & $0.52(-81)$ & $0.49(-60)$ & $0.58(-74)$ \\
\hline & WRF-CMAQ & $0.87(-69)$ & $1.17(-58)$ & $0.92(-25)$ & $0.77(-65)$ \\
\hline \multirow{3}{*}{$R$} & NICAM-g6str & -0.02 & 0.41 & 0.55 & 0.59 \\
\hline & NICAM-g6 & -0.49 & -0.28 & -0.05 & 0.16 \\
\hline & WRF-CMAQ & 0.08 & 0.33 & 0.37 & -0.23 \\
\hline \multirow{4}{*}{$\operatorname{RMSE}\left(\mu \mathrm{g} \mathrm{m}^{3}\right)$} & NICAM-g6str & 2.62 & 2.33 & 0.72 & 1.85 \\
\hline & NICAM-g6 & 2.52 & 2.45 & 1.10 & 2.06 \\
\hline & WRF-CMAQ & 2.18 & 1.83 & 0.88 & 1.98 \\
\hline & & \multicolumn{4}{|c|}{ Sulfate } \\
\hline \multirow{4}{*}{$\begin{array}{l}\text { Average }\left(\mu \mathrm{g} \mathrm{m}^{3}\right) \text { and difference }(\%) \\
\text { (vs. observation) in brackets }\end{array}$} & Observation & $4.79(-6)$ & $2.86(44)$ & $4.18(-32)$ & $4.85(-12)$ \\
\hline & NICAM-g6str & $4.51(-34)$ & $4.14(11)$ & $2.84(-46)$ & $4.25(-26)$ \\
\hline & NICAM-g6 & $3.17(-21 \%)$ & $3.17(42 \%)$ & $2.25(-21 \%)$ & $3.58(-22 \%)$ \\
\hline & WRF-CMAQ & 3.77 & 4.08 & 3.30 & 3.80 \\
\hline \multirow{3}{*}{$R$} & NICAM-g6str & 0.01 & 0.50 & 0.51 & 0.73 \\
\hline & NICAM-g6 & 0.05 & 0.56 & 0.86 & 0.75 \\
\hline & WRF-CMAQ & 0.41 & 0.02 & 0.87 & 0.78 \\
\hline \multirow{4}{*}{$\operatorname{RMSE}\left(\mu \mathrm{g} \mathrm{m}^{3}\right)$} & NICAM-g6str & 3.61 & 2.81 & 2.71 & 2.49 \\
\hline & NICAM-g6 & 3.01 & 2.30 & 2.49 & 2.77 \\
\hline & WRF-CMAQ & 2.30 & 3.37 & 1.62 & 2.56 \\
\hline & & \multicolumn{4}{|c|}{$\mathrm{SO}_{2}$} \\
\hline \multirow{3}{*}{$\begin{array}{l}\text { Average (ppbv) and difference } \\
(\%) \text { (vs. observation) } \\
\text { in brackets }\end{array}$} & Observation & 2.74 & 2.28 & 2.35 & 3.79 \\
\hline & NICAM-g6str & $1.25(-54)$ & $1.90(-17)$ & $2.34(-1)$ & $2.34(-38)$ \\
\hline & NICAM-g6 & $2.42(-12)$ & $2.45(7)$ & $2.52(7)$ & $3.21(-15)$ \\
\hline \multirow{2}{*}{$R$} & NICAM-g6str & 0.02 & -0.04 & 0.62 & 0.21 \\
\hline & NICAM-g6 & -0.64 & -0.52 & 0.22 & -0.04 \\
\hline \multirow{2}{*}{ RMSE (ppbv) } & NICAM-g6str & 1.82 & 0.93 & 0.97 & 2.08 \\
\hline & NICAM-g6 & 1.29 & 0.94 & 0.85 & 1.29 \\
\hline
\end{tabular}



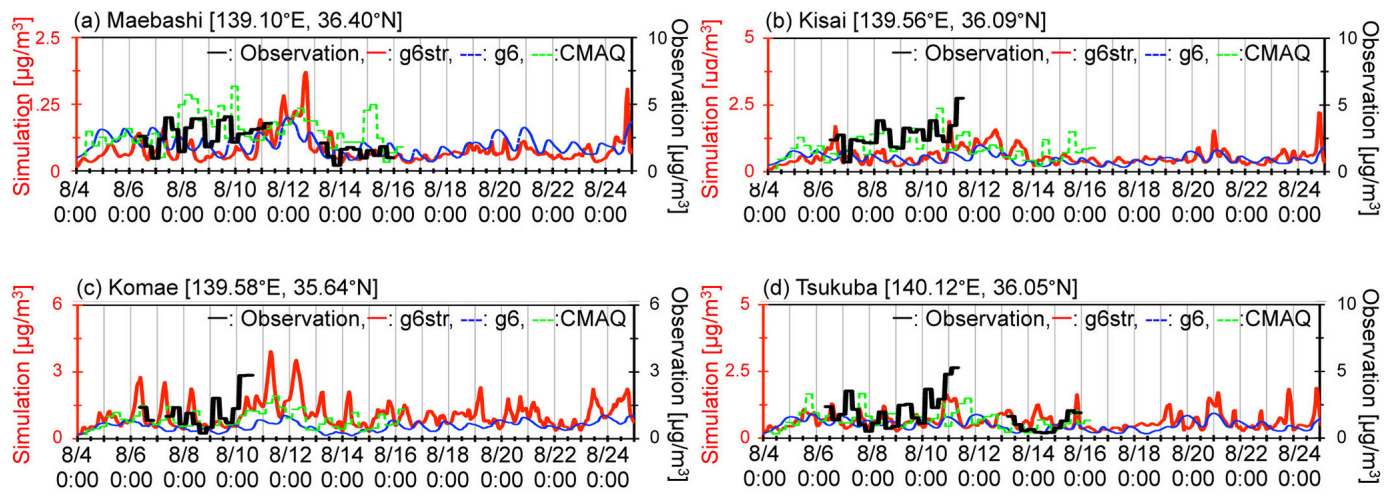

Figure 11. Temporal variations in the simulated (NICAM-g6str, NICAM-g6, and WRF-CMAQ) and observed EC mass concentrations near the surface at (a) Maebashi, (b) Kisai, (c) Komae and (d) Tsukuba in August 2007. The WRF-CMAQ results are given by Shimadera et al. (2013). The left axis in red represents the simulated values, and the right axis in black represents the observed values, in units of $\mu g \mathrm{~m}^{3}$.
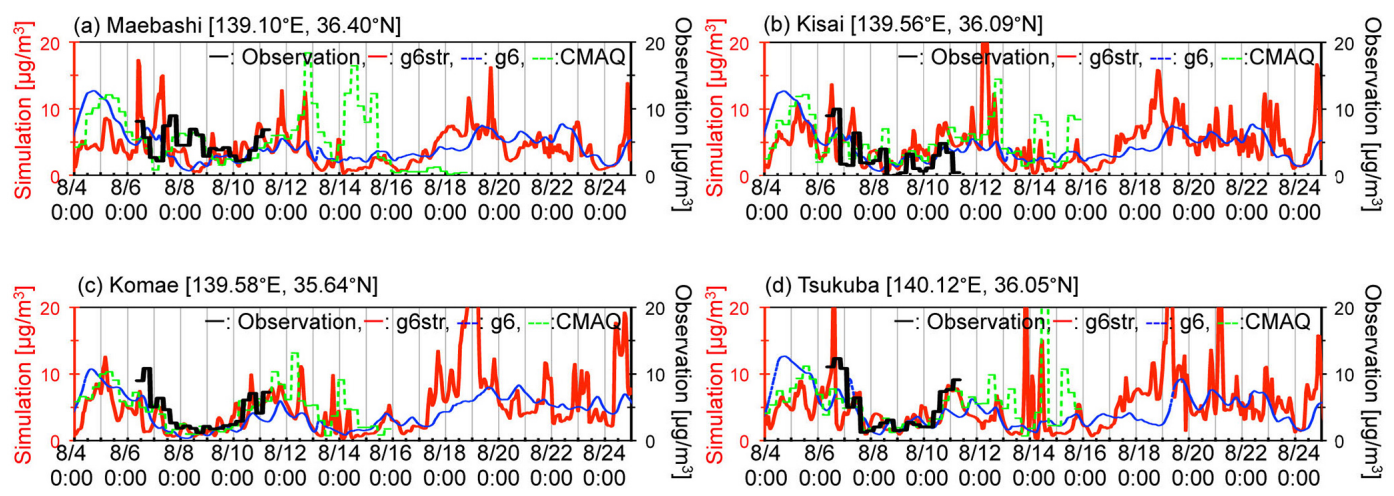

Figure 12. Same as Fig. 11 but for sulfate.

within approximately $20 \%$ at all sites, with the exception of NICAM-g6str at Maebashi and NICAM-g6str at Tsukuba (Table 2). The temporal variations in the simulated $\mathrm{SO}_{2}$ concur with those in the observations. The observations sometimes show high $\mathrm{SO}_{2}$ concentrations at all sites, e.g., up to $20 \mathrm{ppbv}$ at Komae, in the afternoon on 12 and $14 \mathrm{Au}-$ gust. On 12 August, NICAM-g6str normally reproduced the peaks of the observed $\mathrm{SO}_{2}$, but with the blunter and slightly shifted peaks. In the NICAM-g6str simulation, the strong $\mathrm{SO}_{2}$ plumes from industrial sources over the Tokyo Bay arrived at the inner areas such as Kisai. On 14 August, although the NICAM-g6str-simulated winds were comparable to the observed ones (Figs. 7 and 8), NICAM-g6str did not reproduce the sharp peaks of the observed $\mathrm{SO}_{2}$, especially at Komae and Tsukuba. It may imply that special meteorological fields cause the observed peaks on 12 August, whereas unaccounted $\mathrm{SO}_{2}$ emission from local sources or sporadic volcanoes is stronger on 14 August. The latter issue is improved by processing time highly resolved emission inventories of $\mathrm{SO}_{2}$, which can be estimated through a top-down approach using a data assimilation (Schutgens et al., 2012; Xu et al., 2013).
To assess the performance of both NICAM-gs6tr and NICAM-g6 in simulating the distributions of the air pollutants over Japan, we compared the August averages of the simulated EC, sulfate and $\mathrm{SO}_{2}$ concentrations with the available measurements (Figs. 14 and 15). Although the EC observatories are limited, both the NICAM-g6str and NICAMg6 simulated EC concentrations are much underestimated compared to the observations, with the relative bias $\left(B_{\mathrm{r}}\right)$, defined as a ratio of the simulated value to the observed one, to be 0.15 (NICAM-g6str) and 0.16 (NICAM-g6). In China, the NICAM-g6str-simulated EC concentrations are comparable to the NICAM-g6-simulated ones with the $R$ values of 0.71 (NICAM-g6str) and 0.68 (NICAM-g6), whereas in Japan (no available measurements), the NICAM-g6strsimulated EC concentrations are larger than NICAM-g6simulated ones in the Japanese urban areas such as Nagoya $\left(136.97^{\circ} \mathrm{E}, 35.17^{\circ} \mathrm{N}\right)$ and Osaka $\left(135.54^{\circ} \mathrm{E}, 34.68^{\circ} \mathrm{N}\right)$.

The NICAM-g6str-simulated sulfate concentrations are larger and more comparable to the observations over China compared to NICAM-g6-simulated ones. In Japan, the hot spots with greater concentrations of more than $5 \mu \mathrm{g} \mathrm{m}{ }^{3}$ are found only in the NICAM-g6str results. The $B_{\mathrm{r}}$ values are 

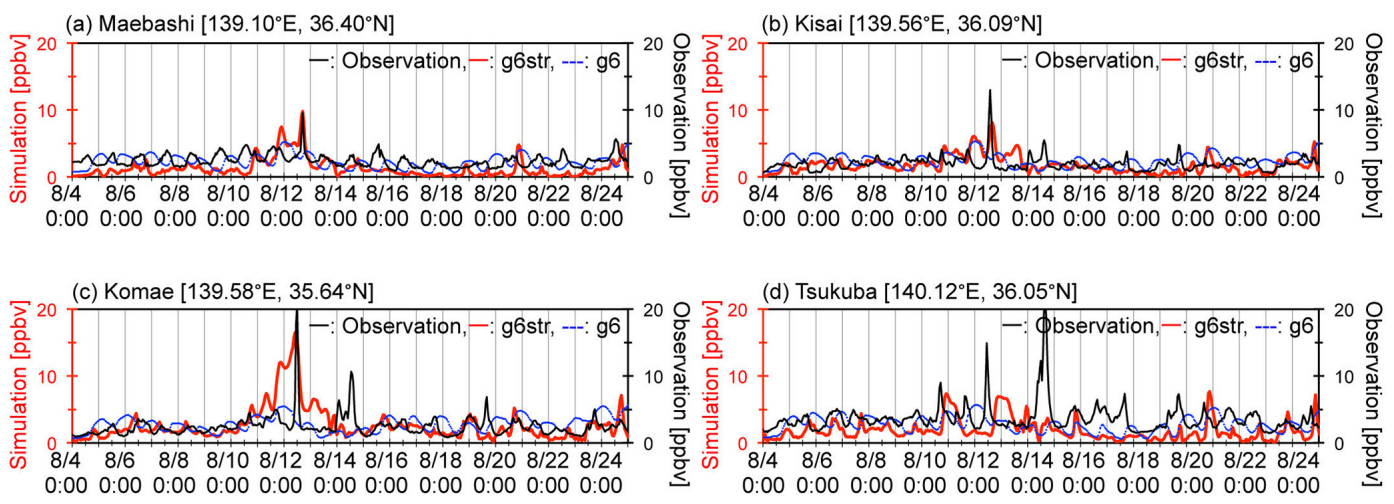

Figure 13. Same as Fig. 12 but for $\mathrm{SO}_{2}$ without the WRF-CMAQ results, in units of ppbv.
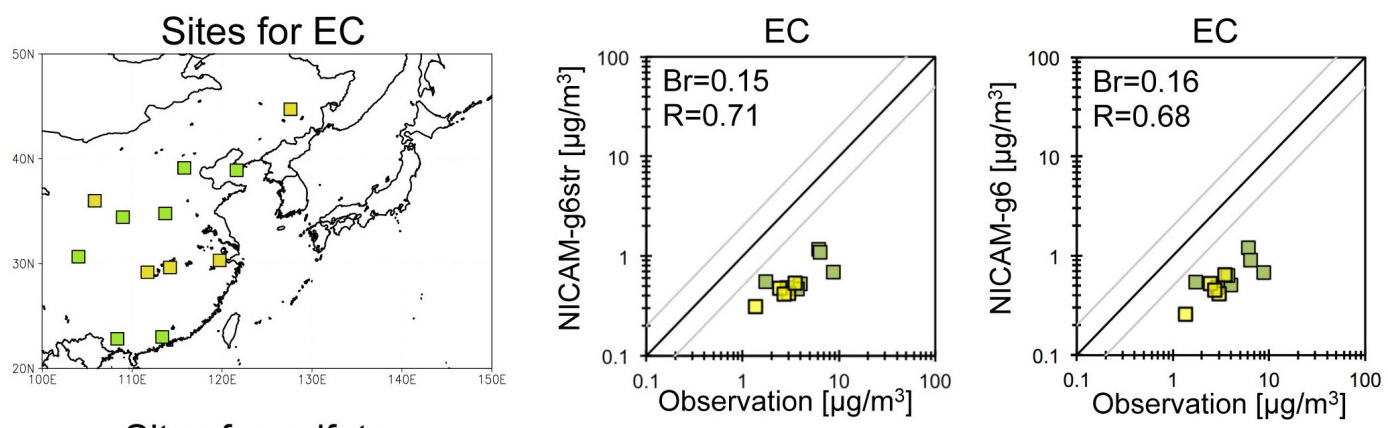

Sites for sulfate
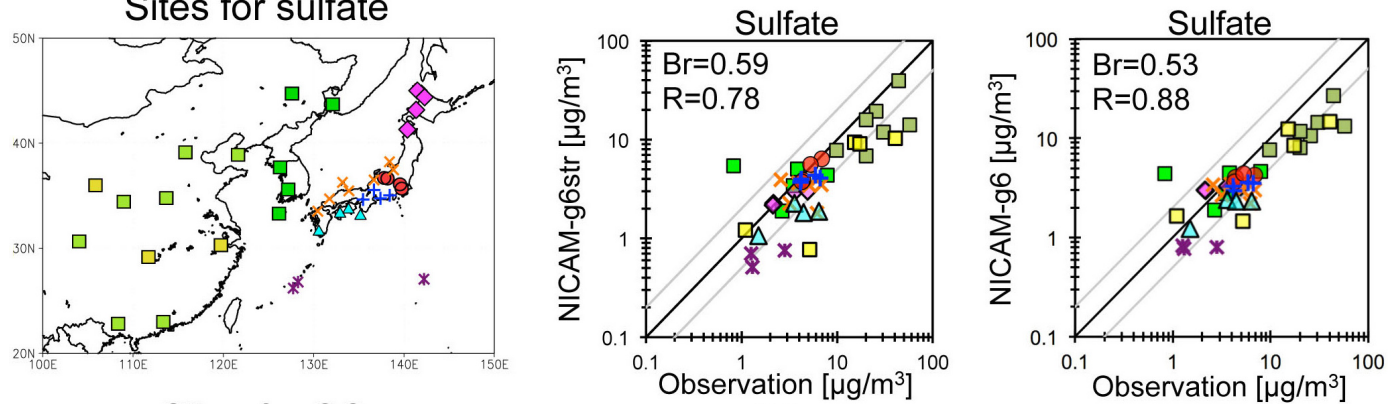

Sites for $\mathrm{SO}_{2}$
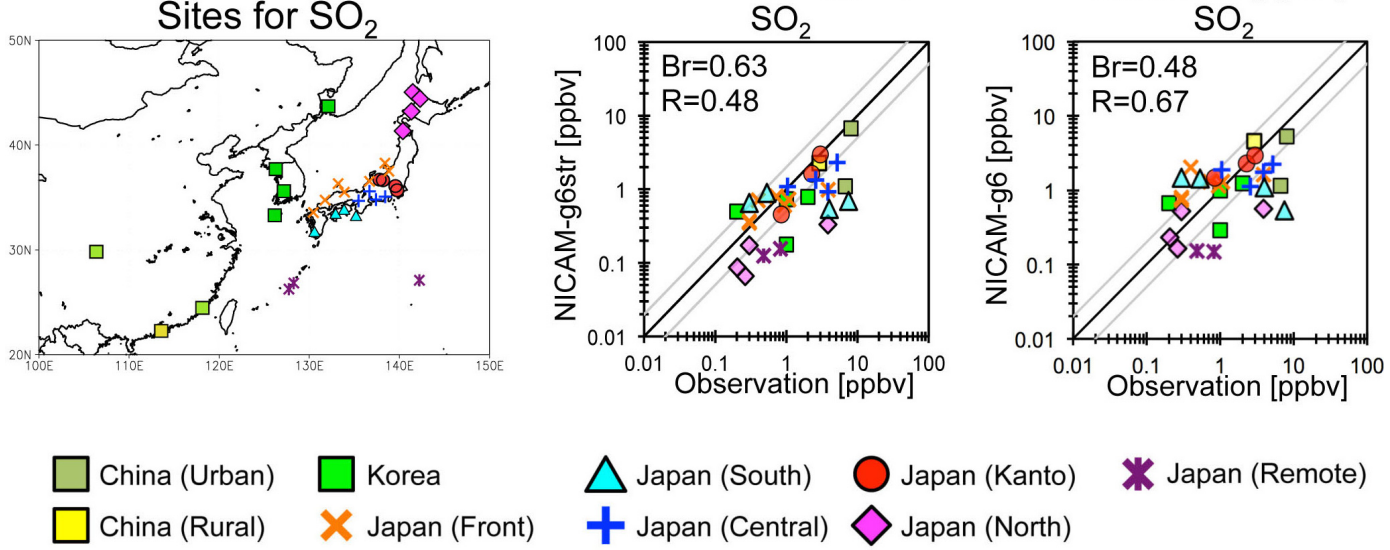

Japan (Remote)

Figure 14. Scatterplot of August mean concentrations for EC, sulfate and $\mathrm{SO}_{2}$ between the simulations by NICAM-g6str and NICAM-g6 and the observations at the sites shown in the left panels. The statistics parameters, relative bias $\left(B_{\mathrm{r}}\right)$ and correlation coefficient $(R)$, calculated by the simulated and observed concentrations at all the sites, are also shown in each panel. 


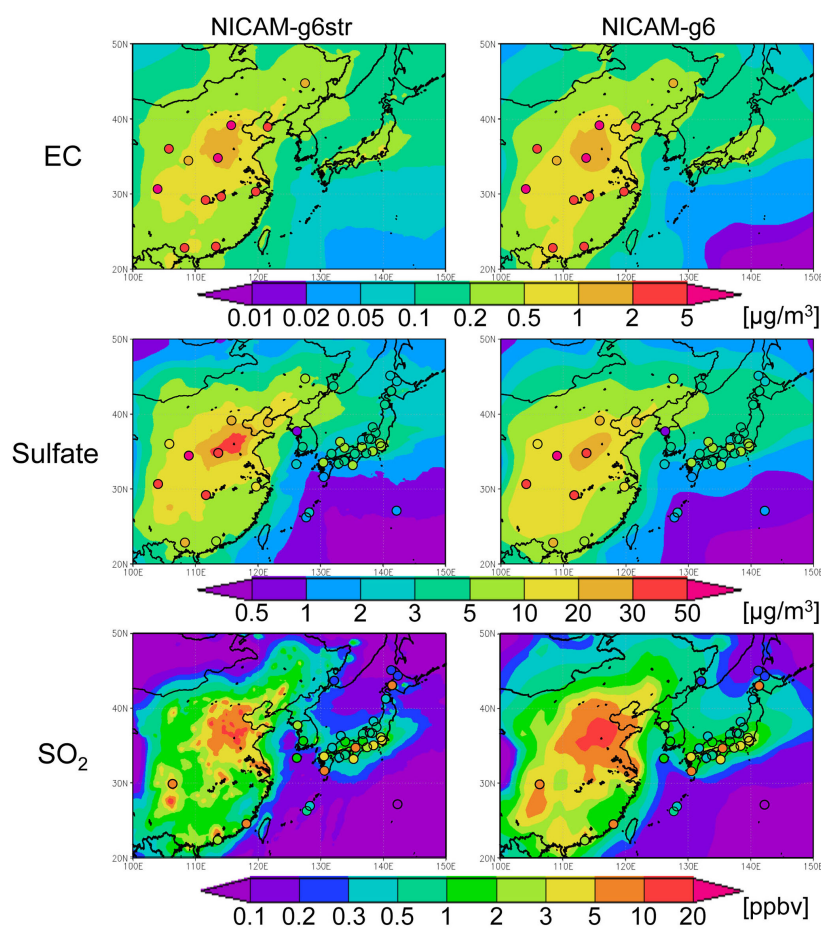

Figure 15. Horizontal distributions of concentrations for EC, sulfate and $\mathrm{SO}_{2}$ near the surface using NICAM-g6str and NICAM-g6 in August averages. The circles in color show the observation results at the sites.

estimated to be 0.59 (NICAM-g6str) and 0.53 (NICAM-g6), whereas the $R$ values are estimated to be 0.78 (NICAMg6str) and 0.88 (NICAM-g6), respectively. The results indicate that the sulfate concentrations obtained by both NICAM-g6str and NICAM-g6 tend to be underestimated by approximately $40-50 \%$ compared with the observed sulfate concentrations. The underestimation over East Asia is mainly caused by the underestimation in China and possibly by the uncertainty of the simulated precipitation around Japan. At Hedo, located at the Okinawa islands, for example, the underestimation of both NICAM-g6str and NICAM-g6 simulated sulfate concentrations is caused by a possible underestimation of transboundary sulfate from the continent, which is attributed to a large uncertainty of the precipitation fields modulated by typhoon in the early August. However, the correlations of sulfate between the simulations (both NICAMg6str and NICAM-g6) and observations are adequately acceptable. The simulated and observed $\mathrm{SO}_{2}$ concentrations also correlate, with the $R$ value of 0.63 (NICAM-g6str) and 0.48 (NICAM-g6). The $B_{\mathrm{r}}$ values are calculated to be 0.48 (NICAM-g6str) and 0.67 (NICAM-g6). Figure 15 shows that the $\mathrm{SO}_{2}$, which is a primary product, is localized near the source areas, whereas sulfate, which is as a secondary product, is distributed from the source to the outflow areas. Although EC is also a primary product, the horizontal distributions of NICAM-g6str-simulated EC are larger than those (a) EC mass concentration at FAMIKA sites

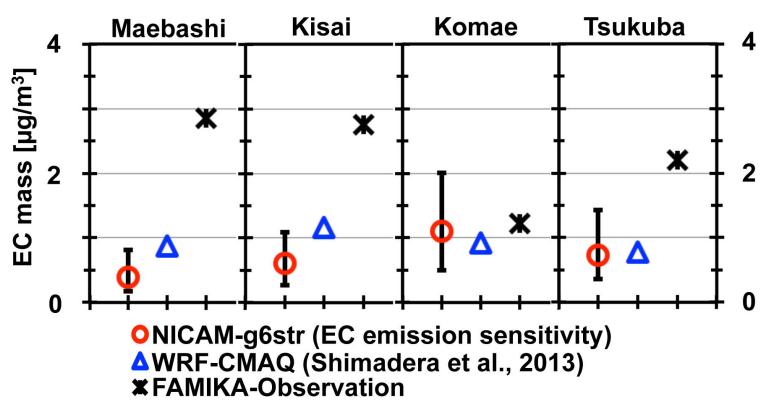

(b) Sulfate mass concentration at FAMIKA sites

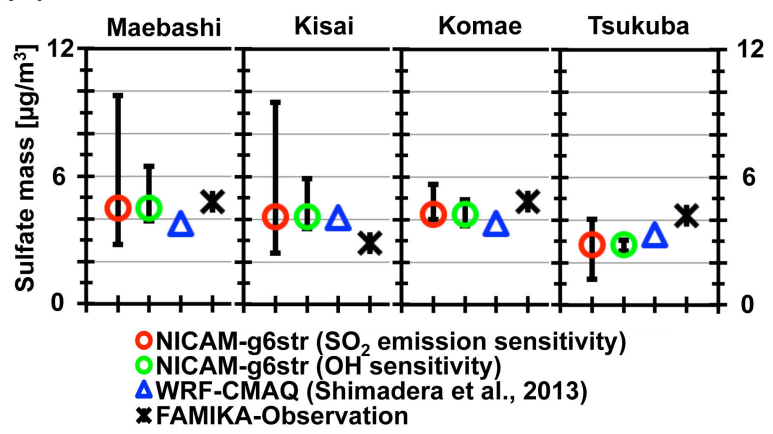

Figure 16. (a) EC and (b) sulfate mass concentrations at the four FAMIKA sites using NICAM-g6str under the sensitivity experiments, WRF-CMAQ results shown by Shimadera et al. (2013) and the FAMIKA observations in averages of 6-11 August. The bar represents the range of the sensitivity.

of NICAM-g6str-simulated $\mathrm{SO}_{2}$, possibly because EC is less scavenged through the dry deposition and oxidation processes compared to $\mathrm{SO}_{2}$.

\subsubsection{Uncertainty in the simulation}

Sensitivity tests were conducted to examine potential uncertainties derived from prescribed data sets related to EC and sulfate for the NICAM-g6str simulations. For the EC sensitivity tests, the emission quantities were set to half and twice of those used in the standard run in this study. The results for the FAMIKA sites are shown in Fig. 16a in which the bars show the simulated EC concentrations for both sensitivity tests. For the majority of the sites, with the exception of Komae, the results obtained by the sensitivity experiments of twice strength remain underestimated compared with the measurements. The large underestimation of the EC mass concentrations at Maebashi and Kisai was also shown by WRF-CMAQ of Shimadera et al. (2013) as well as the previous studies of WRF-CMAQ in Morino et al. (2010a, b) and Chatani et al. (2014). However, Fushimi et al. (2011) and Chatani et al. (2014) suggested that the difference in the EC concentrations between WRF-CMAQ and the measurements is largely attributed to an underestimation of the $\mathrm{EC}$ emission inventory, especially open biomass burning from domestic 
sources. The local EC emission can be estimated by a combination of the data assimilation and intensive measurements (Schutgens et al., 2012; Wang et al., 2012; Yumimoto and Takemura, 2013).

Sensitivity experiments of the $\mathrm{SO}_{2}$ emissions and the prescribed $\mathrm{OH}$ radical used in sulfur chemistry were executed under half and twice the amounts used in the standard experiment. The results for the FAMIKA sites are shown in Fig. 16b in which the bars show the simulated sulfate concentrations for both sensitivity tests under the different experiments. Compared with the $\mathrm{SO}_{2}$ emissions used in the standard experiment, the doubled amount of $\mathrm{SO}_{2}$ emissions can overcome the slight underestimation of the simulated sulfate compared with the observations. Therefore, the emission inventories of $\mathrm{SO}_{2}$ should be improved for better simulation of the sulfate.

In this sensitivity tests for oxidants, the $\mathrm{SO}_{2}$ oxidation by $\mathrm{OH}$ radical strongly depends on the $\mathrm{OH}$ concentrations as well as the cloud cover area, whereas the $\mathrm{SO}_{2}$ oxidation by ozone and hydrogen peroxide mainly depends on their concentrations, the cloud cover area, and the cloud water content. The cloud distributions are modulated by some feedbacks of the sulfate formation through the aerosol direct and indirect effects. As a result, the sensitivity of the $\mathrm{OH}$ radical concentrations to the simulated sulfate concentration is smaller than that we expected and that to the $\mathrm{SO}_{2}$ emissions. We also determined that the sensitivities of the other oxidants to the simulated sulfate concentrations were small (not shown). These results and Figs. 14 and 15 also suggest that the use of the prescribed oxidants for sulfate formation is not crucial for predicting monthly and weekly averaged sulfate mass concentrations at least by taking into account for diurnal and seasonal variations of the prescribed oxidants. At the same time, they also suggest that, because the relationship between the oxidants and the sulfate concentrations through the feedbacks is non-linear and complex, the use of the prescribed oxidants for sulfate formation can affect the hourly variations of the sulfate concentrations, and thus the sensitivity of the oxidants to the simulated sulfate should be investigated.

\subsection{3 $\mathbf{P M}_{2.5}$}

Figure 17 shows the temporal variation in the surface $\mathrm{PM}_{2.5}$ mass concentration at the 18 Japanese sites including 10 sites in the Kanto area using different $y$ axes for the observed and simulated values. At most of the sites, both NICAMg6str and NICAM-g6 usually captures the synoptic variation of the observed $\mathrm{PM}_{2.5}$, whereas only NICAM-g6str reproduces the diurnal variation of the observed $\mathrm{PM}_{2.5}$. Table 3 shows the $\mathrm{PM}_{2.5}$ concentrations in daily, daytime (from 9 a.m. to 4 p.m.), and nighttime (from 9 p.m. to 4 a.m.) averages and ratios of daytime to nighttime. The results show that the simulated $\mathrm{PM}_{2.5}$ concentrations are underestimated compared with the observations by more than a factor of two and by up to four at Maebashi. As for the diurnal variation, the results show that the NICAM-g6str-simulated ratios (0.9-1.3) are larger than NICAM-g6-simulated ones (0.8$0.9)$, whereas the NICAM-g6str-simulated ones are smaller than the observed values (1.0-1.8). At Maebashi, where the ratio is higher than that at the other sites, the issue of the poor model performance of the meteorological fields can be a major reason of the large underestimation, as mentioned in Sect. 3.1. At all sites, especially Maebashi and Kisai, the possible underestimation of SOA may be a critical issue, as shown in the fact that the clear diurnal variation of $\mathrm{PM}_{2.5}$ during 4-9 August and the high value of the ratios from daytime to nighttime and suggested by previous studies (Matsui et al., 2009; Morino et al., 2010c). Morino et al. (2010c) implied that over the Kanto area SOA from anthropogenic sources, which were disregarded in this study, are large portion of total carbonaceous aerosols, even though WRF-CMAQ does not correctly reproduce such carbonaceous aerosols. More sophisticated SOA module, e.g., volatility basis-set approach proposed by Donahue et al. (2006) based on the categorization of organic vapors with similar volatility, is required for to produce SOA with higher accuracy. Originally, the underestimation of $\mathrm{PM}_{2.5}$ was common among previous studies that employed regional aerosol-transport models (Morino et al., 2010b, Chatani et al., 2011), primarily because the concentrations of the observed $\mathrm{PM}_{2.5}$ include undefined chemical species with mean fractions ranging from approximately 30 to $50 \%$ in the total $\mathrm{PM}_{2.5}$ in the summer of Japan (data sets from the Tokyo Environment Agency and the Kawasaki Municipal Research Institute for Environmental Protection). Another possible reason is that the $\mathrm{PM}_{2.5}$ mass concentration includes water attached to aerosols, depending on the ambient RH conditions. Therefore, these undefined chemical compounds in this study may account for a large portion of the difference between the simulated and the observed values.

To evaluate the vertical profiles of the $\mathrm{PM}_{2.5}$ mass concentrations, we used the LIDAR observation operated by the NIES-Japan network. Figure 18 shows the average results for the simulated and observed extinction coefficient of the spherical particles at Tsukuba and Chiba in August. At both sites, the vertical profiles and the magnitudes below $3 \mathrm{~km}$ height of the simulated extinction by both NICAM-g6str and NICAM-g6 are comparable to the observed results, whereas the simulated extinction values tend to be smaller than the observed extinction values near the surface. These results near the surface are consistent with those obtained by the surface $\mathrm{PM}_{2.5}$ comparison shown in Fig. 17. In contrast, the extinction values observed by LIDAR include large variabilities, primarily because they are retrieved from the surface to the cloud base, which highly varies hour-by-hour and is basically difficult to detect with high accuracy, and secondly because they depend not only on the $\mathrm{PM}_{2.5}$ mass concentrations but also on the ambient RH and the water amount attached to aerosols. At both sites, the differences in the ex- 
Table 3. $\mathrm{PM}_{2.5}$ concentrations in daily, daytime (from 9 a.m. to 4 p.m.), and nighttime (from 9 p.m. to 4 a.m.) averages and mean ratios of daytime to nighttime using the simulations (NICAM-g6str and NICAM-g6) and the observation at seven selected sites in August.

\begin{tabular}{|c|c|c|c|c|c|c|c|}
\hline & Maebashi & Kawasaki & Toride & Hasuda & Sapporo & Nagoya & Fukuoka \\
\hline & \multicolumn{7}{|c|}{ Daily mean $\mathrm{PM}_{2.5}\left(\mu \mathrm{g} \mathrm{m}^{3}\right)$ and standard deviation $\left(\mu \mathrm{g} \mathrm{m}^{3}\right)$} \\
\hline Observation & $24.9 . \pm 12.8$ & $23.2 . \pm 12.9$ & 17.6. \pm 9.7 & $20.6 . \pm 11.5$ & 12.7. \pm 6.3 & 17.3. \pm 10.1 & 14.3. \pm 7.5 \\
\hline NICAM-g6str & $6.4 . \pm 3.9$ & 10.0. \pm 7.3 & $9.0 . \pm 6.3$ & $8.4 . \pm 5.0$ & 4.9. \pm 3.5 & $7.5 . \pm 5.7$ & $3.4 . \pm 2.6$ \\
\hline \multirow[t]{2}{*}{ NICAM-g6 } & $6.7 . \pm 3.0$ & $6.7 . \pm 3.3$ & $6.7 . \pm 3.4$ & $6.7 . \pm 3.0$ & 4.7. \pm 4.1 & 5.4. \pm 3.0 & $3.5 . \pm 2.3$ \\
\hline & \multicolumn{7}{|c|}{ Daytime (9 a.m.-4 p.m.) mean $\mathrm{PM}_{2.5}\left(\mu \mathrm{g} \mathrm{m}{ }^{3}\right)$ and standard deviation $\left(\mu \mathrm{g} \mathrm{m}{ }^{3}\right)$} \\
\hline Observation & 28.6. \pm 14.1 & 19.4. \pm 12.1 & 15.8. \pm 9.0 & $21.0 . \pm 10.0$ & 15.0. \pm 5.2 & 11.3. \pm 5.4 & $9.7 . \pm 5.7$ \\
\hline NICAM-g6str & 5.9. \pm 3.8 & 7.1. \pm 4.3 & $6.8 . \pm 4.4$ & 7.2. \pm 4.5 & 5.3. \pm 2.8 & $3.5 . \pm 2.3$ & 1.6. \pm 0.8 \\
\hline \multirow[t]{2}{*}{ NICAM-g6 } & $5.0 . \pm 1.7$ & $4.0 . \pm 2.1$ & $4.0 . \pm 2.4$ & 4.4. \pm 1.9 & 7.4. \pm 4.5 & 2.4. \pm 0.9 & 1.4. \pm 0.5 \\
\hline & \multicolumn{7}{|c|}{ Nighttime (9 p.m.-4 a.m.) mean $\mathrm{PM}_{2.5}\left(\mu \mathrm{g} \mathrm{m}^{3}\right)$ and standard deviation $\left(\mu \mathrm{g} \mathrm{m}^{3}\right)$} \\
\hline Observation & $24.4 . \pm 11.9$ & $24.5 . \pm 11.8$ & 16.9. \pm 9.6 & 18.5. \pm 10.3 & 10.7. \pm 6.6 & 19.1. \pm 8.2 & 15.4. \pm 6.7 \\
\hline NICAM-g6str & 7.5. \pm 3.6 & 14.2. \pm 9.2 & $12.1 . \pm 7.6$ & 10.8. \pm 5.5 & $4.1 . \pm 3.9$ & $12.0 . \pm 4.6$ & $5.1 . \pm 3.1$ \\
\hline NICAM-g6 & 7.5. \pm 2.3 & $9.1 . \pm 1.5$ & $8.8 . \pm 2.1$ & $8.4 . \pm 3.0$ & $2.6 . \pm 3.1$ & $7.8 . \pm 1.3$ & 4.4. \pm 2.2 \\
\hline \multicolumn{8}{|c|}{ Ratio of daytime-mean $\mathrm{PM}_{2.5}$ to nighttime-mean $\mathrm{PM}_{2.5}$} \\
\hline Observation & $1.8 . \pm 0.8$ & 1.7. \pm 0.5 & 1.3. \pm 0.4 & 1.2. \pm 0.4 & $1.0 . \pm 0.4$ & $1.3 . \pm 0.4$ & $1.1 . \pm 0.3$ \\
\hline NICAM-g6str & $1.1 . \pm 0.6$ & $1.3 . \pm 0.7$ & 1.1. \pm 0.6 & $1.1 . \pm 0.5$ & $0.9 . \pm 0.3$ & $1.2 . \pm 0.9$ & $1.0 . \pm 0.6$ \\
\hline NICAM-g6 & $0.9 . \pm 0.2$ & $0.8 . \pm 0.1$ & $0.8 . \pm 0.1$ & $0.8 . \pm 0.1$ & $0.8 . \pm 0.2$ & $0.9 . \pm 0.2$ & $0.8 . \pm 0.2$ \\
\hline
\end{tabular}

tinction between NICAM-g6str and NICAM-g6 are small below $1 \mathrm{~km}$ height, whereas those are relatively large above $1 \mathrm{~km}$ height. The differences are attributed to the differences in the primary particles, mainly carbonaceous aerosols, between NICAM-g6str and NICAM-g6 (not shown). It means that it is attributed to the difference in the vertical transport between different spatial resolutions. Therefore, impacts of the difference in the spatial resolution on the distributions of both aerosols and their precursors should be addressed in future work.

\section{Summary}

An aerosol-coupled global nonhydrostatic model, which is based on the aerosol module of the Spectral RadiationTransport Model for Aerosol Species (SPRINTARS) and the global cloud-resolving model of Nonhydrostatic Icosahedral Atmospheric Model (NICAM), with a horizontal resolution of approximately $10 \mathrm{~km}$ or less in the target region, is proposed in the present study. Circulations over both the global and target domains are solved with a single model, whose mesh size varies with fine meshes covering the target region, to calculate meso-scale circulations in the study region. The stretched global model requires lower computational costs to simulate atmospheric aerosols with fine horizontal resolutions compared with the global uniform nonhydrostatic model, whereas it may require higher computational costs compared with the general regional models, because the stretched-grid system calculates inside and outside the target domain. As opposed to the general regional models, the stretched-grid system requires neither nesting techniques nor boundary conditions.

In this study, we developed the new-type regional model with a horizontal resolution of approximately $10 \mathrm{~km}$ to simulate aerosols over Japan, especially in the megacities of the Kanto area, including Tokyo. To evaluate the model performances in the stretched-grid system (hereafter referred to as the "NICAM-g6str"), we also simulated NICAMSPRINTARS with the globally uniformed grid simulation in glevel-6 resolution (the horizontal resolution is set to $110 \mathrm{~km}$ and we call it "NICAM-g6"). Both NICAM-g6str and NICAM-g6 well reproduce general circulations obtained by reanalysis of NCEP-FNL under the nudging technique over Asia including the target region. Only NICAM-g6str usually reproduces both diurnal and synoptic variations of the observed weather (temperature, wind, and precipitation) around Japan. Both NICAM-g6str and NICAM-g6 generally reproduce monthly mean distributions of the observed sulfate and $\mathrm{SO}_{2}$ over East Asia, with high correlations of more than 0.5 , but underestimation of the simulated concentrations by $40 \%$ (NICAM-g6str) and $50 \%$ (NICAM-g6). The underestimation is mainly caused by the underestimation in China and possibly by the uncertainty of the simulated precipitation around Japan. In the Kanto area, the results obtained by NICAM-g6str are much closer to the observations compared to those obtained by NICAM-g6. Only NICAM-g6str succeeds in simulating the wind patterns and the diurnal transitions around the center of the Kanto area, although it is in- 

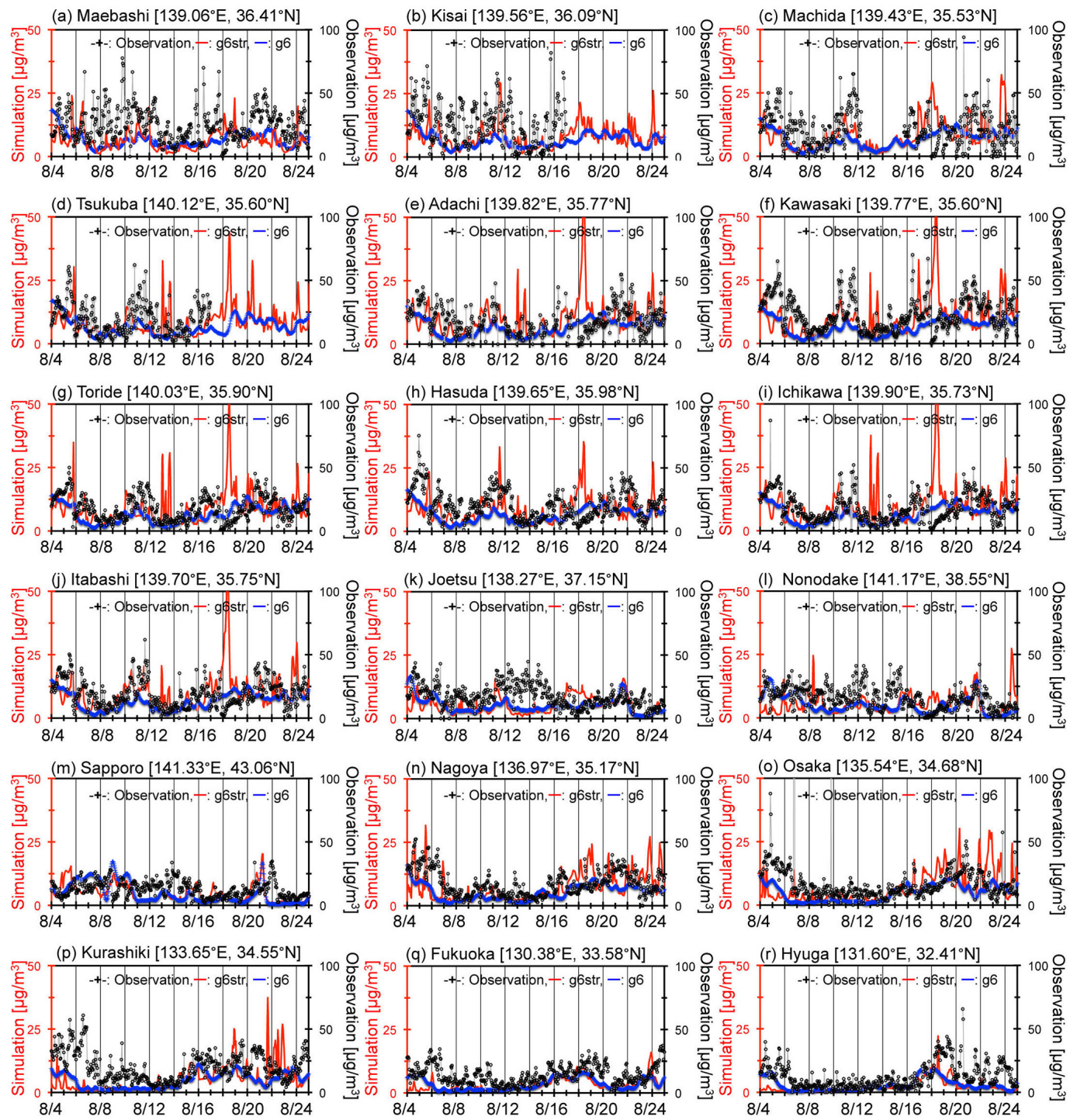

Figure 17. Temporal variations in the NICAM-g6str and NICAM-g6 simulated and observed PM 2.5 near the surface at 18 Japanese sites in August 2007. The left axis in red represents the simulated values, and the right axis in black represents the observed values, in units of $\mu \mathrm{g} \mathrm{m}^{-3}$.

adequate to simulate the wind patterns and the diurnal transitions at some sites located at the edge of the Kanto area and surrounded on three sides by mountains, e.g., Maebashi, mainly due to the insufficient horizontal resolution. NICAMg6str also generally reproduces both diurnal and synoptic variations of the observed and/or a regional aerosol-transport model (WRF-CMAQ) simulated EC, sulfate, and $\mathrm{SO}_{2}$ concentrations, especially with their high correlation $(R>0.5)$ at Komae/Tokyo. The standard and sensitivity experiments suggest that (1) emission inventories of $\mathrm{EC}$ and $\mathrm{SO}_{2}$ should be improved for the better simulation and (2) the use of the prescribed oxidants for the sulfate formation is not crucial for predicting weekly and monthly averaged sulfate mass concentrations at least if the diurnal and seasonal variations of the prescribed oxidants are considered. As for $\mathrm{PM}_{2.5}$ simulations, only NICAM-g6str captures both synoptic and diurnal cycles of $\mathrm{PM}_{2.5}$, with the exception of the underestimation of the simulated $\mathrm{PM}_{2.5}$ by at least twice, probably due to the underestimation of secondary organic aerosol (SOA) from anthropogenic sources and the high uncertainties of the measurements.

Therefore, this new seamless aerosol-transport model, which covers global to regional scales, can be applied to regional simulations. It suggests that even the simplified aerosol module (e.g., prescribed oxidants for sulfur chemistry) is applicable for the regional simulation if the module is coupled to a dynamic core with high horizontal resolution. To more accurately simulate areas around Japan and 

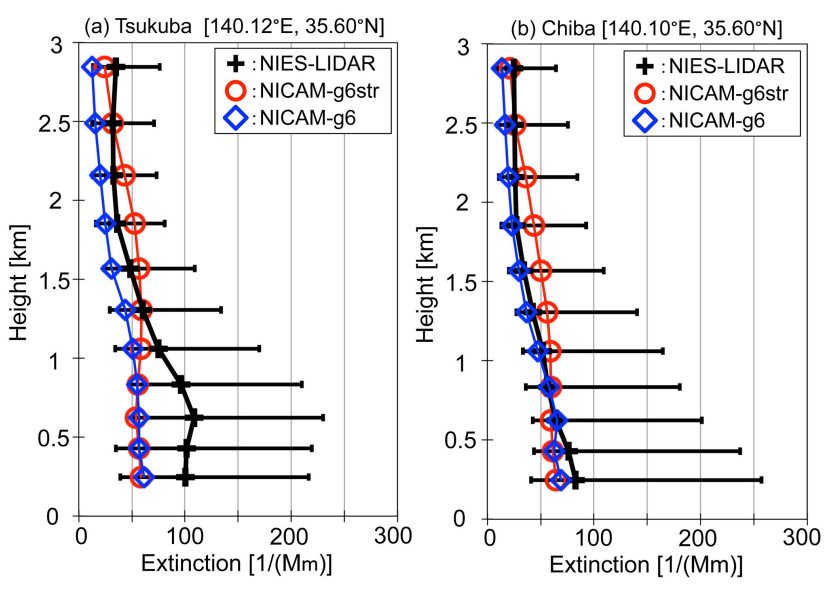

Figure 18. Extinction coefficients in August averages for the spherical particles simulated by NICAM-g6str and NICAM-g6 and the spherical particles observed by the NIES-LIDAR network at (a) Tsukuba and (b) Chiba, in units of $1(\mathrm{Mm})^{-1}$. The bars represent the 25 th and 75 th percentiles of the LIDAR observations.

develop the simplified aerosol module, we need to address the following objectives: (1) to increase the horizontal resolution (less than $10 \mathrm{~km}$ ) to properly resolve wind fields, which can greatly influence the delivery of air pollution from Tokyo to subcities such as Maebashi; (2) to accurately reproduce the cloud and precipitation fields caused by thermal lows, for example, by applying the finer horizontal resolution and/or more sophisticated schemes of cloud microphysics such as the double-moment bulk scheme proposed by Seiki and Nakajima (2014); (3) to use better emission inventories by developing a data assimilation such as the Kalman smoother proposed by Schutgens et al. (2012) with intensive measurements in many sites; (4) to simulate strong peaks of $\mathrm{PM}_{2.5}$ in the daytime in the Kanto region by implementing more sophisticated module of SOA formed from both anthropogenic and biogenic sources, such as the volatility basis-set approach proposed by Donahue et al. (2006), in this model; and (5) to treat nitrate aerosol through a thermodynamic equilibrium in the simulation of wintertime and/or future scenarios where the relative contribution of nitrate will be larger than that of sulfate under the changes in emission of $\mathrm{NO}_{\mathrm{x}}$ and $\mathrm{SO}_{2}$ (e.g., Ohara et al., 2007). These issues are directly connected to the further development of NICAMSPRINTARS in both regional and global simulations. Near the future, we will present scenario experiments on regional scales of $10 \mathrm{~km}$ grids and/or address the issue of regional air quality and its health impacts in densely populated megacities.

Acknowledgements. We acknowledge the developers of NICAM and SPRINTARS, especially K. Suzuki and T. Takemura, and the researchers from FAMIKA, especially S. Hasegawa and Y. Morino, and Y. R. Li and A. Miyaji for their assistance with processing the data sets. We are grateful to the GTOPO30 courtesy of the US Geological Survey, the NCEP-FNL, EAGrid2000 by A. Kannari, and the local government measurements provided by the Tokyo Environment Agency, the Gunma Prefectural Institute of Public Health and Environmental Sciences and the Kawasaki Municipal Research Institute for Environmental Protection. We are also grateful to the working group members of Project SALSA and the Ministry of Education, Culture, Sports and Science and Technology (MEXT). Some of the authors were supported by Project SALSA, which is part of the Research Program on Climate Change Adaptation (RECCA) by the MEXT in Japan, the Global Environment Research Fund S-12 and A-1101 of the Ministry of the Environment (MOE) in Japan, MOE/GOSAT, JST/CREST/EMS/TEEDDA, JAXA/EarthCARE, GCOM-C, MEXT/VL for climate diagnostics and MEXT/KAKENHI/Innovative Areas 2409. The model simulations were performed using supercomputer resources SR16000 and PRIMEHPC FX10 from the University of Tokyo, Japan. Some of the authors were supported by Project SALSA, which is part of the Research Program on Climate Change Adaptation (RECCA) by the MEXT in Japan, the Global Environment Research Fund S-12 and A-1101 of the Ministry of the Environment (MOE) in Japan, the Grant-in-Aid for Scientific Research on Innovative Areas (Grant Number 24110002), the Grant-in-Aid for Young Scientist B (Grant Number 26740010), MOE/GOSAT, JST/CREST/EMS/TEEDDA, JAXA/EarthCARE, GCOM-C, MEXT/VL for climate diagnostics and MEXT/KAKENHI/Innovative Areas 2409.

Edited by: A. Lauer

\section{References}

Aonashi, K., Awaka, J., Hirose, M., Kozu, T., Kubota, T., Liu, G., Shige, S., Kida, S., Seto, S., Takahashi, N., and Takayabu, Y. N.: GSMaP passive, microwave precipitation retrieval algorithm: Algorithm description and validation, J. Meteor. Soc. Japan, 87A, 119-136, 2009.

Arakane, S., Satoh, M., and Yanase, W.: Excitation of deep convection to the north of tropical storm Bebinca (2006), J. Meteorol. Soc. Japan, 92, 141-161, doi:10.2151/jmsj.2014-201, 2014.

Arakawa, A. and Schubert, W. H.: Interactions of cumulus cloud ensemble with the large-scale environment, part I, J. Atmos. Sci., 31, 674-701, doi:10.1175/15200469(1974)031<0674:IOACCE>2.0.CO;2, 1974.

Barrie, L. A., Yi, Y., Leaitch, W. R., Lohmann, U., Kasibhatla, P., Roelofs, G.-J., Wilson, J., McGovern, F., Benkovitz, C., Melieres, M. A., Law, K., Prospero, J., Kritz, M., Bergmann, D., Bridgeman, C., Chin, M., Christensen, J., Easter, R., Feichter, J., Land, C., Jeuken, A., Kjellstrom, E., Koch, D., and Rasch, P.: A comparison of large-scale atmospheric sulphate aerosol models (COSAM): overview and highlights, Tellus, 53B, 615-645, 2001.

Berry, E. X.: Cloud droplet growth by collection, J. Atmos. Sci., 24, 688-701, 1967.

Chatani, S., Morikawa, T., Nakatsuka, S., and Matsunaga, S.: Sensitivity analysis of domestic emission sources and transboundary transport on PM2.5 concentrations in three major Japanese urban areas for the year 2005 with the three-dimensional aie quality 
simulation, J. Jpn. Soc. Atmos. Environ., 46, 101-110, 2011 (in Japanese).

Chatani, S., Morino, Y., Shimadera, H., Hayami, H., Mori, Y., Sasaki, K., Kajino, M., Yokoi, T., Morikawa, T., and Ohara, T.: Multi-model analyses of dominant factors influencing elemental carbon in Tokyo metropolitan area of Japan, Aerosol Air Qual. Res., 14, 396-405, 2014.

Chow, J. C., Watson, J. G., Crow, D., Lowenthal, D. H., and Merrifield, T.: Comparison of IMPROVE and NIOSH carbon measurements, Aerosol Sci. Technol., 34, 23-34, 2001.

Dai, T., Goto, D., Schutgens, N. A. J., Dong, X., Shi, G., and Nakajima, T.: Simulated aerosol key optical properties over global scale using an aerosol transport model coupled with a new type of dynamic core, Atmos. Environ., 82, 71-82, doi:10.1016/j.atmosenv.2013.10.018, 2014a.

Dai, T., Schutgens, N. A. J., Goto, D., Shi, G., and Nakajima, T.: Improvement of aerosol optical properties modeling over Eastern Asia with MODIS AOD assimilation in a global non-hydrostatic icosahedral aerosol transport model, Environ. Pollut., 195, 319329, doi:10.1016/j.envpol.2014.06.021, 2014b.

Diehl, T., Heil, A., Chin, M., Pan, X., Streets, D., Schultz, M., and Kinne, S.: Anthropogenic, biomass burning, and volcanic emissions of black carbon, organic carbon, and $\mathrm{SO}_{2}$ from 1980 to 2010 for hindcast model experiments, Atmos. Chem. Phys. Discuss., 12, 24895-24954, doi:10.5194/acpd-12-24895-2012, 2012.

Dockery, D. W., Pope III, C. A., Xu, X., Spengler, J. D., Ware, J. H., Fay, M. E., Ferris Jr., B. G., and Speizer, F. E.: An association between air pollution and mortality in six U.S. cities, New Engl. J. Med., 329, 1753-1759, doi:10.1056/NEJM199312093292401, 1993.

Donahue, N. M., Robinson, A. L., Stanier, C. O., and Pandis, S. N.: Coupled partitioning, dilution, and chemical aging of semivolatile organics, Environ. Sci. Technol., 40, 2635-2643, 2006.

Forster, P., Ramaswamy, V., Artaxo, P., Berntsen, T., Betts, R., Fahey, D. W., Haywood, J., Lean, J., Lowe, D. C., Myhre, G., Nganga, J., Prinn, R., Raga, G., Schulz, M., and Van Dorland, R.: Changes in Atmospheric Constituents and in Radiative Forcing, in: Climate Change 2007: The Physical Science Basis. Contribution of Working Group I to the Fourth Assessment Report of the Intergovernmental Panel on Climate Change, edited by: Solomon, S., Qin, D., Manning, M., Chen, Z., Marquis, M., Averyt, K. B., Tignor, M., and Miller, H. L., Cambridge University Press, Cambridge, United Kingdom and New York, NY, USA, 996 pp., 2007.

Fushimi, A., Wagai, R., Uchida, M., Hasegawa, S., Takahashi, K., Kondo, M., Hirabayashi, M., Morino, Y., Shibata, Y., Ohara, T., Kobayashi, S., and Tanabe, K.: Radiocarbon $\left({ }^{14} \mathrm{C}\right)$ diurnal variations in fine particles at sites downwind from Tokyo, Japan in summer, Environ. Sci. Technol., 45, 6784-6792, doi:10.1021/es201400p, 2011.

Goto, D.: Modeling of black carbon in Asia using a global-toregional seamless aerosol-transport model, Environ. Pollut., 195, 330-335, doi:10.1016/j.envpol.2014.06.006, 2014.

Goto, D., Nakajima, T., Takemura, T., and Sudo, K.: A study of uncertainties in the sulfate distribution and its radiative forcing associated with sulfur chemistry in a global aerosol model,
Atmos. Chem. Phys., 11, 10889-10910, doi:10.5194/acp-1110889-2011, 2011a.

Goto, D., Schutgens, N. A. J., Nakajima, T., and Takemura, T.: Sensitivity of aerosol to assumed optical properties over Asia using a global aerosol model and AERONET, Geophys. Res. Lett., 38, L17810, doi:10.1029/2011GL048675, 2011b.

Goto, D., Takemura, T., Nakajima, T., and Badarinath, K. V. S.: Global aerosol model-derived black carbon concentration and single scattering albedo over Indian region and its comparison with ground observations, Atmos. Environ., 45, 3277-3285, doi:10.1016/j.atmosenv.2011.03.037, 2011c.

Hallquist, M., Wenger, J. C., Baltensperger, U., Rudich, Y., Simpson, D., Claeys, M., Dommen, J., Donahue, N. M., George, C., Goldstein, A. H., Hamilton, J. F., Herrmann, H., Hoffmann, T., Iinuma, Y., Jang, M., Jenkin, M. E., Jimenez, J. L., Kiendler-Scharr, A., Maenhaut, W., McFiggans, G., Mentel, Th. F., Monod, A., Prévôt, A. S. H., Seinfeld, J. H., Surratt, J. D., Szmigielski, R., and Wildt, J.: The formation, properties and impact of secondary organic aerosol: current and emerging issues, Atmos. Chem. Phys., 9, 5155-5236, doi:10.5194/acp-9-51552009, 2009.

Hasegawa, S., Kobayashi, S., Ohara, T., Tanabe, K., Hayami, H., Yomemochi, S., Umezawa, N., Iijima, A., and Kumagai, K.: Fine aerosol measurement and modeling in Kanto area (1), overview of measurement, Proceedings of the 49th Annual Meeting of the Japan Society for Atmospheric Environment, p. 377, 2008 (in Japanese).

Holloway, T., Sakurai, T., Han, Z., Ehlers, S., Spak, S. N., Horowitz, L. W., Carmichael, G. R., Streets, D. G., Hozumi, Y., Ueda, H., Park, S. U., Fung, C., Kajino, M., Thongboonchoo, N., Engardt, M., Bennet, C., Hayami, H., Sartelet, K., Wang, Z., Matsuda, K., and Amann, M.: MICS-Asia II: Impact of global emissions on regional aiq quality in Asia, Atmos. Environ., 42, 3543-3561, 2008.

Kannari, A., Tonooka, Y. Baba, T., and Murano, K.: Development of multiple-species $1 \mathrm{~km} \times 1 \mathrm{~km}$ resolution hourly basis emissions inventory for Japan, Atmos. Environ., 41, 3428-3439, 2007.

Kawabata, T., Kuroda, T., Seko, H., and Saito, K.: A CloudResolving 4DVAR Assimilation Experiment for a Local Heavy Rainfall Event in the Tokyo Metropolitan Area, Mon. Weather Rev., 139, 1911-1931, 2011.

Kinne, S., Schulz, M., Textor, C., Guibert, S., Balkanski, Y., Bauer, S. E., Berntsen, T., Berglen, T. F., Boucher, O., Chin, M., Collins, W., Dentener, F., Diehl, T., Easter, R., Feichter, J., Fillmore, D., Ghan, S., Ginoux, P., Gong, S., Grini, A., Hendricks, J., Herzog, M., Horowitz, L., Isaksen, I., Iversen, T., Kirkevåg, A., Kloster, S., Koch, D., Kristjansson, J. E., Krol, M., Lauer, A., Lamarque, J. F., Lesins, G., Liu, X., Lohmann, U., Montanaro, V., Myhre, G., Penner, J., Pitari, G., Reddy, S., Seland, O., Stier, P., Takemura, T., and Tie, X.: An AeroCom initial assessment - optical properties in aerosol component modules of global models, Atmos. Chem. Phys., 6, 1815-1834, doi:10.5194/acp-6-1815-2006, 2006.

Kitada, T., Okamura, K., and Tanaka, S.: Effects of topography and urbanization on local winds and thermal environment in the Nohbi Plain, coastal region of central Japan: A numerical analysis by mesoscale meteorological model with a k-e turbulence model, J. Applied Met., 37, 1026-1046, 1998. 
Kubota, T., Shige, S., Hashizume, H., Aonashi, K., Takahashi, N., Seto, S., Hirose, M., Takayabu, Y. N., Nakagawa, K., Iwanami, K., Ushio, T., Kachi, M., and Okamoto, K.: Global Precipitation Map using Satelliteborne Microwave Radiometers by the GSMaP Project: Production and Validation, IEEE T. Geosci. Remote Sens., 45, 2259-2275, 2007.

Kurokawa, J., Ohara, T., Morikawa, T., Hanayama, S., JanssensMaenhout, G., Fukui, T., Kawashima, K., and Akimoto, H.: Emissions of air pollutants and greenhouse gases over Asian regions during 2000-2008: Regional Emission inventory in ASia (REAS) version 2, Atmos. Chem. Phys., 13, 11019-11058, doi:10.5194/acp-13-11019-2013, 2013.

Kusaka, H. and Hayami, H.: Numerical simulation of local weather for a high photochemical oxidant event using the WRF model, JSME International J. Ser. B. Fluids and thermal engineering, 49, 72-77, 2006.

Kuwagata, T. and Sumioka, M.: The daytime PBL heating process over complex terrain in central Japan under fair and calm weather conditions, Part III: Daytime thermal low and nocturnal thermal high, J. Met. Soc. Japan, 69, 91-104, 1991.

Le Treut, H. and Li, Z.-X.: Sensitivity of an atmospheric general circulation model to prescribed SST changes: feedback effects associated with the simulation of cloud optical properties, Clim. Dynam., 5, 175-187, 1991.

Matsui, H., Koike, M., Takegawa, N., Kondo, Y., Griffin, R. J., Miyazaki, Y., Yokouchi, Y., and Ohara, T.: Secondary organic aerosol formation in urban air: Temporal variations and possible contributions from unidentified hydrocarbons, J. Geophys. Res., 114, D04201, doi:10.1029/2008JD010164, 2009.

Mellor, G. L. and Yamada, T.: A hierarchy of turbulence closure models for planetary boundary layers, J. Atmos. Sci., 31, 1791-1806, doi:10.1175/15200469(1974)031<1791:AHOTCM>2.0.CO;2, 1974.

Miura, H., Satoh, M., Nasuno, T., Noda, A. T., and Oouchi, K.: A Madden-Julian Oscillation event realistically simulated by a global cloud-resolving model, Science, 318, 1763-1765, doi:10.1126/science.1148443, 2007.

Morino, Y., Chatani, S., Hayami, H., Sasaki, K., Mori, Y., Morikawa, T., Ohara, T., Hasegawa, S., and Kobayashi, S.: Evaluation of ensemble approach for $\mathrm{O}_{3}$ and $\mathrm{PM}_{2.5}$ simulation, Asian J. Atmos. Environ., 4, 150-156, 2010a.

Morino, Y., Chatani, S., Hayami, H., Sasaki, K., Mori, Y., Morikawa, T., Ohara, T., Hasegawa, S., and Kobayashi, S.: Inter-comparison of chemical transport models and evaluation of model performance for $\mathrm{O}_{3}$ and $\mathrm{PM}_{2.5}$ prediction - case study in the Kanto Area in summer 2007, J. Jpn. Soc. Atmos. Environ., 45, 212-226, 2010 b (in Japanese).

Morino, Y., Takahashi, K., Fushimi, A., Tanabe, K., Ohara, T., Hasegawa, S., Uchida, M., Takami, A., Yokouchi, Y., and Kobayashi, S.: Contrasting diurnal variations in fosil and nonfossil secondary organic aerosols in urban outflow, Japan, Environ. Sci. Technol., 44, 8581-8586, 2010c.

Nakajima, T., Tsukamoto, M., Tsushima, Y., Numaguti, A., and Kimura, T.: Modeling of the radiative process in an atmospheric general circulation model, Appl. Optics, 39, 4869-4878, doi:10.1364/AO.39.004869, 2000.

Nakanishi, M. and Niino, H.: An improved Mellor-Yamada level 3 model with condensation physics: Its design and verification, Bound.-Lay. Meteorol., 112, 1-31, doi:10.1023/B:BOUN.0000020164.04146.98, 2004.

Nakanishi, M. and Niino, H.: Development of an improved turbulence closure model for the atmospheric boundary layer, J. Meteorol. Soc. Japan, 87, 895-912, doi:10.2151/jmsj.87.895, 2009.

Nasuno, T.: Forecast skill of Madden-Julian Oscillation events in a global nonhydrostatic model during the CINDY2011/DYNAMO observation period, SOLA, 9, 69-73, doi:10.2151/sola.2013016, 2013.

Niwa, Y., Tomita, H., Satoh, M., and Imasu, R.: A threedimensional icosahedral grid advection scheme preserving monotonicity and consistency with continuity for atmospheric tracer transport, J. Meteorol. Soc. Jpn., 89, 255-268, doi:10.2151/jmsj.2011-306, 2011.

Noda, A. T., Oouchi, K., Satoh, M., Tomita, H., Iga, S., and Tsushima, Y.: Importance of the subgrid-scale turbulent moist process of the turbulent transport: On cloud distribution in global cloud-resolving simulations, Atmos. Res., 96, 208-217, doi:10.1016/j.atmosres.2009.05.007, 2009.

Ohara, T., Akimoto, H., Kurokawa, J., Horii, N., Yamaji, K., Yan, X., and Hayasaka, T.: An Asian emission inventory of anthropogenic emission sources for the period 1980-2020, Atmos. Chem. Phys., 7, 4419-4444, doi:10.5194/acp-7-4419-2007, 2007.

Okamoto, K., Iguchi, T., Takahashi, N., Iwanami, K., and Ushio, T.: The global satellite mapping of precipitation (GSMaP) project, 25th IGARSS Proceedings, 3414-3416, 2005.

Pope III, C. A., Ezzati, M., and Dockery, D. W.: Fine-particulate air pollution and life expectancy in the United States, N. Engl. J. Med., 360, 376-386, doi:10.1056/NEJMsa0805646, 2009.

Ramanathan, V., Akimoto, H., Bonasoni, P., Brauer, M., Carmichael, G., Chung, C. E., Feng, Y., Fuzzi, S., Hasnain, S. I., Iyngararasan, M., Jayaraman, A., Lawrence, M. G., Nakajima, T., Panwar, T. S., Ramana, M. V., Rupakheti, M., Weidemann, S., and Yoon, S.-C.: Atmosphere brown clouds and regional climate change, part I of atmosphere brown clouds: Regional assessment report with focus on Asia, Project Atmosphere Brown Cloud, United National Environment Programme, Nairobi, Kenya, 2008.

Randall, D. A., Heikes, R., and Ringler, T.: Global atmospheric modeling using a geodesic grid with an isentropic vertical coordinate, in: General Circulation Model Development, Academic Press, San Diego, CA, 509-538, 2000.

Saito, K., Fujita, T., Yamada, Y., Ishida, J., Kumagai, Y., Aranami, K., Ohmori, S., Nagasawa, R., Kumagai, S., Muroi, C., Kato, T., Eito, H., and Yamazaki, Y.: The Operational JMA Nonhydrostatic Mesoscale Model, Mon. Weather Rev., 134, 1266-1298, doi:10.1175/MWR3120.1, 2006.

Sato, T., Miura, H., Satoh, M., Takayabu, Y. N., and Wang, Y.: Diurnal cycle of precipitation in the tropics simulated in a global cloud-resolving model, J. Climate, 22, 4809-4826, doi:10.1175/2009JCLI2890.1, 2009.

Satoh, M., Matsuno, T., Tomita, H., Miura, H., Nasuno, T., and Iga, S.: Nonhydrostatic Icosahedral Atmospheric Model (NICAM) for global cloud resolving simulations, J. Comput. Phys., 227, 3486-3514, doi:10.1016/j.jcp.2007.02.006, 2008.

Satoh, M., Inoue, T., and Miura, H: Evaluations of cloud properties of global and local cloud system resolving models us- 
ing CALIPSO and CloudSat simulators, J. Geophys. Res., 115, D00H14, doi:10.1029/2009JD012247, 2010.

Satoh, M., Tomita, H., Yashiro, H., Miura, H., Kodama, C., Seiki, T., Noda, A., Yamada, T., Goto, D., Sawada, M., Miyoshi, T., Niwa, Y., Hara, M., Ohno, T., Iga, S., Arakawa, T., Inoue, T., and Kubokawa, H.: The Non-hydrostatic icosahedral atmospheric model: description and development, Prog. Earth Planet. Sci., 1, 18-49, doi:10.1186/s40645-014-0018-1, 2014.

Schutgens, N., Nakata, M., and Nakajima, T.: Estimating aerosol emissions by assimilating remote sensing observations into a global transport model, Remote Sens., 4, 3528-3542, doi:10.3390/rs4113528, 2012.

Seiki, T. and Nakajima, T.: Aerosol effects of the condensation process on a convective cloud simulation, J. Atmos. Sci., 71, 833853, doi:10.1175/JAS-D-12-0195.1, 2014.

Sekiguchi, M. and Nakajima, T.: A $k$-distribution-based radiation code and its computational optimization for an atmospheric general circulation model, J. Quant. Spectrosc. R., 109, 2779-2793, doi:10.1016/j.jqsrt.2008.07.013, 2008.

Shimadera, H., Hayami, H., Morino, Y., Ohara, T., Chatani, S., Hasegawa, S., and Kaneyasu, N.: Analysis of summertime atmospheric transport of fine particulate matter in northeast Asia, Asia-Pac, J. Atmos. Sci., 49, 347-360, doi:10.1007/s13143-0130033-y, 2013.

Shimizu, A., Sugimoto, N., Matsui, I., Arao, K., Uno, I., Murayama, T., Kagawa, N., Aoki, K., Uchiyama, A., and Yamazaki, A.: Continuous observations of Asian dust and other aerosols by polarization lidars in China and Japan during ACE-Asia, J. Geophys. Res., 109, D19S17, doi:10.1029/2002JD003253, 2004.

Stuhne, G. R. and Peltier, W. R.: Vortex erosion and amalgamation in a new model of large scale flow on the sphere, J. Comput. Phys. 128, 58-81, doi:10.1006/jcph.1996.0196, 1996.

Sudo, K., Takahashi, M., Kurokawa, J., and Akimoto, H.: CHASER: A global chemical model of the troposphere: 1. Model description, J. Geophys. Res., 107, 4339, doi:10.1029/2001JD001113, 2002.

Sugimoto, N., Uno, I., Nishikawa, M., Shimizu, A., Matsui, I., Dong, X., Chen, Y., Quan, H.: Record Heavy Asian Dust in Beijing in 2002: Observations and Model Analysis of Recent Events, Geophys. Res. Lett., 30, 1640, doi:10.1029/2002GL016349, 2003.

Suzuki, K., Nakajima, T., Satoh, M., Tomita, H., Takemura, T., Nakajima, T. Y., and Stephens, G. L.: Global cloud-systemresolving simulation of aerosol effect on warm clouds, Geophys. Res. Lett., 35, L19817, doi:10.1029/2008GL035449, 2008.

Takemura, T.: Distributions and climate effects of atmospheric aerosols from the preindustrial era to 2100 along Representative Concentration Pathways (RCPs) simulated using the global aerosol model SPRINTARS, Atmos. Chem. Phys., 12, 1155511572, doi:10.5194/acp-12-11555-2012, 2012.

Takemura, T., Okamoto, H., Maruyama, Y., Numaguti, A., Higurashi, A., and Nakajima, T.: Global three-dimensional simulation of aerosol optical thickness distribution of various origins, J. Geophys. Res., 105, 17853-17873, doi:10.1029/2000JD900265, 2000 .

Takemura, T., Nakajima, T., Dubovik, O., Holben, B. N., and Kinne, S.: Single scattering albedo and radiative forcing of various aerosol species with a global three- dimensional model, J. Climate, 15, 333-352, doi:10.1175/15200442(2002)015<0333:SSAARF>2.0.CO;2, 2002.

Takemura, T., Nozawa, T., Emori, S., Nakajima, T. Y., and Nakajima, T.: Simulation of climate response to aerosol direct and indirect effects with aerosol transport-radiation model, J. Geophys. Res., 110, D02202, doi:10.1029/2004JD005029, 2005.

Taylor, M., Tribbia, J., and Iskandarani, M.: The spectral element method for the shallow water equations on the sphere, J. Comput. Phys., 130, 92-108, doi:10.1006/jcph.1996.5554, 1997.

Textor, C., Schulz, M., Guibert, S., Kinne, S., Balkanski, Y., Bauer, S., Berntsen, T., Berglen, T., Boucher, O., Chin, M., Dentener, F., Diehl, T., Easter, R., Feichter, H., Fillmore, D., Ghan, S., Ginoux, P., Gong, S., Grini, A., Hendricks, J., Horowitz, L., Huang, P., Isaksen, I., Iversen, I., Kloster, S., Koch, D., Kirkevåg, A., Kristjansson, J. E., Krol, M., Lauer, A., Lamarque, J. F., Liu, X., Montanaro, V., Myhre, G., Penner, J., Pitari, G., Reddy, S., Seland, $\varnothing .$, Stier, P., Takemura, T., and Tie, X.: Analysis and quantification of the diversities of aerosol life cycles within AeroCom, Atmos. Chem. Phys., 6, 1777-1813, doi:10.5194/acp-6-1777-2006, 2006.

Tomita, H.: A stretched grid on a sphere by new grid transformation, J. Meteorol. Soc. Jpn., 86A, 107-119, 2008a.

Tomita, H.: New microphysics with five and six categories with diagnostic generation of cloud ice, J. Meteorol. Soc. Jpn., 86A, 121-142, 2008b.

Tomita, H. and Satoh, M.: A new dynamical framework of nonhydrostatic global model using the icosahedral grid, Fluid Dyn. Res., 34, 357-400, 2004.

Tomita, H., Miura, H., Iga, S., Nasuno, T., and Satoh, M.: A global cloud-resolving simulation: Preliminary results from an aqua planet experiment, Geophys. Res. Lett., 32, L08805, doi:10.1029/2005GL022459, 2005.

Tomita, H., Goto, K., and Satoh, M.: A new approach of atmospheric general circulation model: Global cloud resolving model NICAM and its computational performance, SIAM J. Sci. Stat. Comp., 30, 2755-2776, doi:10.1137/070692273, 2008.

Turpin, B. J. and Lim, H.-J.: Species contributions to $\mathrm{PM}_{2.5}$ mass concentrations: revisiting common assumptions for estimating organic mass, Aerosol Sci. Tech., 35, 602-610, doi:10.1080/02786820119445, 2001.

UNEP and WMO: Integrated assessment of black carbon and tropospheric ozone, United Nations Environment Programme (UNEP) and World Meteorological Organization (WMO), Nairobi, Kenya, 2011.

Ushio, T., Kubota, T., Shige, S., Okamoto, K., Aonashi, K., Inoue, T., Takahashi, N., Iguchi, T., Kachi, M., Oki, R., Morimoto, T., and Kawasaki, Z.: A Kalman filter approach to the Global Satellite Mapping of Precipitation (GSMaP) from combined passive microwave and infrared radiometric data, J. Meteor. Soc. Japan, 87A, 137-151, 2009.

Wang, J., Xu, X. Q., Henze, D. K., Zeng, J., Ji, Q., Tsay, S.-C., and Huang, J. P.: Top-down estimate of dust emissions through integration of MODIS and MISR aerosol retrievals with the GEOS-Chem adjoint model, Geophys. Res. Lett., 39, L08802, doi:10.1029/2012GL051136, 2012.

Xu, X. Q., Wang, J., Henze, D. K., Qu, W. J., and Kopacz, M.: Constraints on aerosol source using GEOS-Chem adjoint and MODIS radiances, and evaluation with multisensor 
(OMI, MISR) data, J. Geophys. Res.-Atmos., 118, 6396-6413, doi:10.1002/jgrd.50515, 2013.

Yu, H., Remer, L. A., Chin, M., Bian, H., Tan, Q., Yuan, T., and Zhang, Y.: Aerosols from overseas rival domestic emissions over North America, Science, 337, 566-569, doi:10.1126/science.1217576, 2012.

Yumimoto, K. and Takemura, T.: The SPRINTARS version 3.80/4D-Var data assimilation system: development and inversion experiments based on the observing system simulation experiment framework, Geosci. Model Dev., 6, 2005-2022, doi:10.5194/gmd-6-2005-2013, 2013.

Zhang, Q., Jimenez, J. L., Canagaratna, M. R., Allan, J. D., Coe, H., Ulbrich, I., Alfarra, M. R., Takami, A., Middlebrook, A. M., Sun, Y. L., Dzepina, K., Dunlea, E., Docherty, K., DeCarlo, P. F., Salcedo, D., Onasch, T., Jayne, J. T., Miyoshi, T., Shimono, A., Hatakeyama, S., Takegawa N., Kondo, Y., Schneider, J., Drewnick, F., Borrmann, S., Weimer, S., Demerjian, K., Williams, P., Bower, K., Bahreini, R., Cottrell, L., Griffin, R. J., Rautiainen, J., Sun, J. Y., Zhang, Y. M., and Worsnop, D. R.: Ubiquity and dominance of oxygenated species in organic aerosols in anthropogenically-influenced Northern Hemisphere midlatitudes, Geophys. Res. Lett., 34, L13801, doi:10.1029/2007GL029979, 2007.
Zhang, X. Y., Wang, Y. Q., Niu, T., Zhang, X. C., Gong, S. L., Zhang, Y. M., and Sun, J. Y.: Atmospheric aerosol compositions in China: spatial/temporal variability, chemical signature, regional haze distribution and comparisons with global aerosols, Atmos. Chem. Phys., 12, 779-799, doi:10.5194/acp12-779-2012, 2012. 